\title{
Grid-stretching capability for the GEOS-Chem 13.0.0 atmospheric chemistry model
}

\author{
Liam Bindle ${ }^{1,2}$, Randall V. Martin ${ }^{1,2,3}$, Matthew J. Cooper ${ }^{2,1}$, Elizabeth W. Lundgren ${ }^{4}$, Sebastian D. Eastham ${ }^{5}$, \\ Benjamin M. Auer ${ }^{6}$, Thomas L. Clune ${ }^{6}$, Hongjian Weng ${ }^{7}$, Jintai Lin ${ }^{7}$, Lee T. Murray ${ }^{8}$, Jun Meng ${ }^{2,1,9}$, Christoph \\ A. Keller ${ }^{6,10}$, William M. Putman ${ }^{6}$, Steven Pawson ${ }^{6}$, and Daniel J. Jacob ${ }^{4}$ \\ ${ }^{1}$ Department of Energy, Environmental and Chemical Engineering, Washington University, St. Louis, MO, USA \\ ${ }^{2}$ Department of Physics and Atmospheric Science, Dalhousie University, Halifax, NS, Canada \\ ${ }^{3}$ Harvard-Smithsonian Center for Astrophysics, Cambridge, MA, USA \\ ${ }^{4}$ John A. Paulson School of Engineering and Applied Sciences, Harvard University, Cambridge, MA, USA \\ ${ }^{5}$ Laboratory for Aviation and the Environment, Massachusetts Institute of Technology, Cambridge, MA, USA \\ ${ }^{6}$ Global Modeling and Assimilation Office, NASA Goddard Space Flight Center, Greenbelt, MD, USA \\ ${ }^{7}$ Laboratory for Climate and Ocean-Atmosphere Studies, Department of Atmospheric and Oceanic Sciences, \\ School of Physics, Peking University, Beijing, China \\ ${ }^{8}$ Department of Earth and Environmental Sciences, University of Rochester, Rochester, NY, USA \\ ${ }^{9}$ Atmospheric and Oceanic Sciences, University of California, Los Angeles, Los Angeles, CA, USA \\ ${ }^{10}$ Universities Space Research Association, Columbia, MD, USA
}

Correspondence: Liam Bindle (liam.bindle @wustl.edu)

Received: 25 November 2020 - Discussion started: 16 December 2020

Revised: 28 June 2021 - Accepted: 26 August 2021 - Published: 6 October 2021

\begin{abstract}
Modeling atmospheric chemistry at fine resolution globally is computationally expensive; the capability to focus on specific geographic regions using a multiscale grid is desirable. Here, we develop, validate, and demonstrate stretched grids in the GEOS-Chem atmospheric chemistry model in its high-performance implementation (GCHP). These multiscale grids are specified at runtime by four parameters that offer users nimble control of the region that is refined and the resolution of the refinement. We validate the stretched-grid simulation versus global cubed-sphere simulations. We demonstrate the operation and flexibility of stretched-grid simulations with two case studies that compare simulated tropospheric $\mathrm{NO}_{2}$ column densities from stretched-grid and cubed-sphere simulations to retrieved column densities from the TROPOspheric Monitoring Instrument (TROPOMI). The first case study uses a stretched grid with a broad refinement covering the contiguous US to produce simulated columns that perform similarly to a C180 $(\sim 50 \mathrm{~km})$ cubed-sphere simulation at less than one-ninth the computational expense. The second case study experiments with a large stretch factor for a global stretched-grid
\end{abstract}

simulation with a highly localized refinement with $\sim 10 \mathrm{~km}$ resolution for California. We find that the refinement improves spatial agreement with TROPOMI columns compared to a C90 cubed-sphere simulation of comparable computational demands. Overall, we find that stretched grids in GEOS-Chem are a practical tool for fine-resolution regionalor continental-scale simulations of atmospheric chemistry. Stretched grids are available in GEOS-Chem version 13.0.0.

\section{Introduction}

Global simulations of atmospheric chemistry are computationally demanding. Chemical mechanisms in the troposphere typically involve more than 100 chemical species, emitted by anthropogenic and natural sources, with production and loss by chemical reactions, and mixing through 3-D transport on all scales. Typical global model resolutions are on the order of hundreds of kilometers and generally limited by the degree of model parallelism. Massively parallel models such as GEOS-Chem in its high-performance implemen- 
tation (GCHP; Eastham et al., 2018) can run on more than 1000 cores (Zhuang et al., 2020) with a demonstrated capability of $50 \mathrm{~km}$ resolution. The coarse resolution of global models can lead to systematic errors in applications when scales of variability finer than the model resolution are relevant, such as vertical transport and scavenging by convective updrafts (Mari et al., 2000; Li et al., 2018, 2019), nonlinear chemistry such as $\mathrm{NO}_{x}$ titration (Valin et al., 2011), localized emission sources (Davis et al., 2001; Freitas et al., 2007), a priori profiles for satellite retrievals (Heckel et al., 2011; Goldberg et al., 2017; Kim et al., 2018), and simulated concentrations for population exposure estimates (Punger and West, 2013; Li et al., 2016). Grid refinement is commonly used for simulations that need to capture fine-scale modes of variability. Here we implement grid refinement in GCHP using a technique that stretches the model grid to enhance its resolution in a user-defined region, enabling massively parallel global multiscale simulations of atmospheric chemistry. We validate the implementation, discuss key considerations for stretched-grid simulations, and demonstrate the capability.

The general approaches to grid refinement are nesting, adaptive grids, and grid-stretching. Nesting broadly describes the use of a coarse global grid in combination with finer regional grids. In one-way nesting, a coarse global simulation generates boundary conditions for one or more regional simulations (Miyakoda and Rosati, 1977; Wang et al., 2004; Lin et al., 2020). One-way nesting is simple yet effective when regional feedbacks on the global simulation are not required. In two-way nesting, the coarse global simulation is dynamically coupled to the regional simulations to allow for feedbacks (Zhang et al., 1986; Krol et al., 2005; Yan et al., 2014; Zängl et al., 2015; Feng et al., 2020). Two-way nesting is more complex technically than one-way nesting, but the regional feedbacks from finely resolved chemical and physical processes can improve global simulations of trace gases such as $\mathrm{CO}$ and $\mathrm{O}_{3}$ (Yan et al., 2014, 2016). One-way and two-way nesting are supported by the single-node version of GEOS-Chem "Classic" (Wang et al., 2004; Yan et al., 2014), and by GEOS-Chem using Weather Research and Forecasting (WRF) meteorology (WRF-GC; Lin et al., 2020; Feng et al., 2020). An adaptive grid is a grid that supports dynamic refinement. Adaptive grids allow the refinement to continuously target regions where simulation accuracy is the most sensitive to model resolution (Tomlin et al., 1997; Slingo et al., 2009; Garcia-Menendez and Odman, 2011). Compared to static refinements, adaptive grids can better capture strong chemical gradients, which can improve the representation of nonlinear chemistry and reduce numerical diffusion (Srivastava et al., 2000; Garcia-Menendez et al., 2010). Adaptive grids are promising, but they are inherently complex and have not yet been used for global atmospheric chemistry simulations. Stretched grids are global grids that are "stretched" by an analytic transform to enhance the grid resolution in a region (Courtier and Geleyn, 1988; Krinner et al.,
1997; Fox-Rabinovitz et al., 2006, 2008; McGregor and Dix, 2008; Tomita, 2008; Harris et al., 2016; Uchida et al., 2016). This stretching creates a global grid with a single refinement and smooth gradual changes in resolution. A key advantage of grid-stretching is simplicity. Stretching does not change the logical structure (topology) of the grid, so fundamental changes to the model structure are not required and twoway coupling is inherent. An additional benefit is that lateral boundary conditions are not required. A drawback of gridstretching, however, is that a stretched-grid simulation has a single refinement. The first use of stretched grids for atmospheric chemistry simulations was in Allen et al. (2000) and Park et al. (2004); more recently, Goto et al. (2015) used a stretched grid for a fine-resolution simulation of aerosols in Japan, and Trieu et al. (2017) used a stretched grid for a fineresolution simulation of surface-level $\mathrm{O}_{3}$ in Japan.

Several recent works set the stage for the development of grid-stretching in GEOS-Chem. Long et al. (2015) developed the grid-independent capability of GEOS-Chem. Harris et al. (2016) developed the stretched grid capability for the GFDL Finite-Volume Cubed-Sphere Dynamical Core (FV3), which is used to calculate advection in GCHP. Eastham et al. (2018) developed the capability for GEOS-Chem to operate on cubed-sphere grids in a distributed memory framework for massive parallelization and to use the Model Analysis and Prediction Layer (MAPL; Suarez et al., 2007) of the NASA Global Modeling and Assimilation Office (GMAO) together with the Earth System Modeling Framework (ESMF; Hill et al., 2004) to couple model components. GEOS-Chem version 12.5.0 added grid-independent emissions that produce consistent emissions regardless of the model grid (Weng et al., 2020; The International GEOS-Chem User Community, 2019). Most recently, MAPL version 2 (Thompson et al., 2020) of the NASA GMAO added stretched grid support.

The remainder of the paper is organized as follows. Sect. 2.1 describes GCHP and the gnomonic cubed-sphere model grid. Sect. 2.2 describes the stretching transform, which is based on the Schmidt (1977) transform and follows the methodology of Harris et al. (2016). Sect. 2.3 discusses considerations for stretched-grid simulations and a simple procedure for choosing an appropriate stretch factor. Section 2.4 describes the shared model configuration that is used for all of the simulations in this paper. Section 2.5 validates the stretched-grid implementation by a comparison of simulated oxidants and $\mathrm{PM}_{2.5}$ concentrations from stretchedgrid and cubed-sphere simulations. Finally, case studies in Sect. 3.1 and 3.2 demonstrate and explore grid-stretching in GCHP by considering the application of comparing simulated $\mathrm{NO}_{2}$ columns with regional observations from TROPOspheric Monitoring Instrument (TROPOMI). 


\section{Development of stretched grids in GEOS-Chem}

\subsection{GEOS-Chem in its high-performance implementation (GCHP)}

We use GEOS-Chem version 13.0.0 in its highperformance implementation (GCHP; Eastham et al., 2018). GEOS-Chem, originally described in Bey et al. (2001), simulates tropospheric-stratospheric chemistry by solving 3-D chemical continuity equations. GCHP uses MAPL (Suarez et al., 2007) and ESMF (Hill et al., 2004) to facilitate the coupling of model components and use of the high-performance computing (HPC) infrastructure. The 3-D advection component is the GFDL Finite-Volume CubedSphere Dynamical Core (Putman and Lin, 2007). Columnar operators (Long et al., 2015) are used for columnar or local calculations such as convection and chemical kinetics. Emissions are aggregated, parameterized, and computed with the Harmonized Emissions Component (HEMCO) described in Keller et al. (2014). Stratospheric chemistry is simulated using the Unified Chemistry Extension (UCX) described in Eastham et al. (2014). Offline meteorological data are from the Goddard Earth Observing System (GEOS) data assimilation system (Rienecker et al., 2008; Todling and El Akkraoui, 2018). Emissions and meteorological input data are regridded online by ESMF using the first-order conservative scheme originally described in Ramshaw (1985). GCHP discretizes the atmosphere with a gnomonic cubed-sphere grid with levels extending from the surface to $1 \mathrm{~Pa}$. The cubed-sphere grid has several advantages over a regular latitude-longitude grid, stemming from its more uniform grid boxes that benefit the parallelization and numerical stability of transport (Eastham et al., 2018). The horizontal resolution of a GCHP simulation is a key determinant of its computational demands.

An example of the horizontal grid is illustrated in Fig. 1. A gnomonic cubed-sphere grid is a mosaic of six grids hereafter referred to as "faces". Each face is a logically square grid that is regularly spaced in a gnomonic projection centered on the face. One of the six faces is highlighted in Fig. 1. The position of the faces are fixed, and the center of the first face is $0^{\circ} \mathrm{N}, 10^{\circ} \mathrm{W}$. Hereafter, we refer to a gnomonic cubedsphere grid as simply a "cubed sphere" or a "cubed-sphere grid". The horizontal resolution of a cubed sphere is dictated by its size, which is an even integer denoted with the notation CN (e.g., C180); each face in the six-face mosaic is an $N \times N$ grid. The computational demand of a GCHP simulation is proportional to the total number of grid boxes. Table 1 provides a comparison of cubed-sphere grids and conventional latitude-longitude grids. We note for context that GEOS-Chem Classic can use a $2^{\circ} \times 2.5^{\circ}$ or $4^{\circ} \times 5^{\circ}$ global grid.

Offline meteorological data for GCHP are provided by the GMAO. GCHP uses a local archive of the GEOS-FP or MERRA-2 data product. GEOS-FP is a near real-time anal-

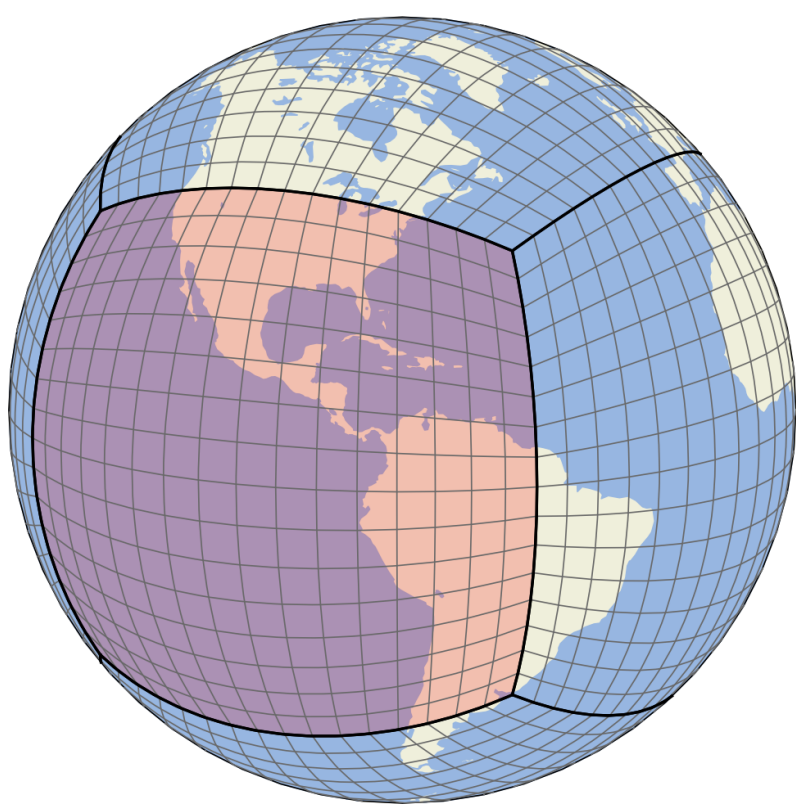

Figure 1. Illustration of a C16 grid. A cubed-sphere grid always has six faces. One of the six faces is highlighted for illustrative purposes. The highlighted face is a $16 \times 16$ grid that is regularly spaced in a gnomonic projection centered on the face.

ysis product with a $0.25^{\circ} \times 0.3125^{\circ}$ grid. MERRA-2 is a reanalysis product with a $0.5^{\circ} \times 0.625^{\circ}$ grid. The effect of topography and surface type on transport is implicit in the meteorological data that drives transport. Both data products have a 72-level terrain-following hybrid-sigma pressure grid that extends from the surface to $1 \mathrm{~Pa}$. GCHP uses a vertical grid that is identical to the meteorological data, and thus vertical regridding is not required.

\subsection{Grid-stretching procedure}

The grid-stretching procedure in GCHP uses a simplified form of the Schmidt (1977) transform for gnomonic cubedsphere grids, following the methodology of Harris et al. (2016). The Schmidt transform can be applied to any grid and effectively stretches the grid to increase its density in a region. The procedure has two steps, starting with a standard cubed-sphere grid. First, the grid is refined at the South Pole by remapping the grid coordinate latitudes with a modified Schmidt transform

$\phi^{\prime}(\phi)=\arcsin \frac{D+\sin \phi}{1+D \sin \phi} \quad$ where $\quad D=\frac{1-S^{2}}{1+S^{2}}$,

where $\phi$ is an input latitude, $\phi^{\prime}$ is the output latitude, and $S$ is a parameter called the "stretch factor". The stretch factor controls the strength of the operation, which effectively attracts the grid coordinates towards the South Pole along meridians. The second step is rotating the entire grid so that the refinement is repositioned to the desired region. The user 
Table 1. Characteristics of various cubed-sphere grids and global latitude-longitude grids.

\begin{tabular}{|c|c|c|c|}
\hline & \multirow{2}{*}{$\begin{array}{r}\text { no. of grid boxes } \\
\text { per level }^{\mathrm{a}}\end{array}$} & \multicolumn{2}{|c|}{ Resolution $^{\mathrm{b}}$} \\
\hline & & Average & Range \\
\hline \multicolumn{4}{|c|}{ Cubed-sphere grids } \\
\hline $\mathrm{C} 24$ & 3456 & $384 \mathrm{~km}$ & $310-461 \mathrm{~km}$ \\
\hline $\mathrm{C} 48$ & 13824 & $192 \mathrm{~km}$ & $153-231 \mathrm{~km}$ \\
\hline C60 & 21600 & $154 \mathrm{~km}$ & $123-185 \mathrm{~km}$ \\
\hline $\mathrm{C} 90$ & 48600 & $102 \mathrm{~km}$ & $82-123 \mathrm{~km}$ \\
\hline C180 & 194400 & $51 \mathrm{~km}$ & $41-62 \mathrm{~km}$ \\
\hline $\mathrm{C} 360$ & 777600 & $26 \mathrm{~km}$ & $20-31 \mathrm{~km}$ \\
\hline \multicolumn{4}{|c|}{ Regular lat-long grids } \\
\hline $4^{\circ} \times 5^{\circ}$ & 3600 & $376 \mathrm{~km}$ & $88-472 \mathrm{~km}$ \\
\hline $2^{\circ} \times 2.5^{\circ}$ & 12960 & $198 \mathrm{~km}$ & $33-249 \mathrm{~km}$ \\
\hline $1^{\circ} \times 1^{\circ}$ & 64800 & $89 \mathrm{~km}$ & $10-111 \mathrm{~km}$ \\
\hline $0.5^{\circ} \times 0.625^{\circ}$ & 207360 & $50 \mathrm{~km}$ & $4-62 \mathrm{~km}$ \\
\hline $0.25^{\circ} \times 0.3125^{\circ}$ & 829440 & $25 \mathrm{~km}$ & $2-31 \mathrm{~km}$ \\
\hline
\end{tabular}

specifies a "target latitude", $T_{\phi}$, and "target longitude", $T_{\theta}$. The refinement is re-centered to these coordinates by rotating the grid.

Figure 2 illustrates the effect of $S$ on stretching a cubedsphere grid. A stretch factor greater than 1 causes stretching. Larger stretch factors cause more stretching and result in a finer and more localized refinement. The resolution at the center of the refinement is approximately $S$ times finer than it was before stretching, and the antipode resolution similarly is approximately $S$ times coarser. These relative changes are approximate since the Schmidt transform is continuous and the grid boxes have nonzero length edges. The grids in Fig. 2 illustrate three noteworthy features of stretched grids: (1) the changes in resolution are smooth, (2) the refined domain diminishes as $S$ increases, and (3) grid boxes outside the refined domain expand. The cubed-sphere face at the center of the refined domain is called the "target face".

The relative change to a grid box size from stretching can be quantified by "local scaling". This quantity represents the effect of grid-stretching at a given point. For a stretch factor of $S$, the local scaling at a given point depends exclusively on how far that point is from the target coordinate. Local scaling, $L$, can be derived from Eq. (1), and expressed as

$L(\Theta ; S)=\frac{1+\cos \Theta+S^{2}(1-\cos \Theta)}{2 S}$,

where $\Theta$ is the angular distance to the target point. Appendix B contains the derivation of Eq. (2). Figure 3 shows local scaling as a function of distance, for stretch factors between 1 and 10. Overlaid are dashed lines that show the lateral position of the face edges after stretching. In the target face, local scaling is approximately $1 / S$ and nearly constant.
The grid is refined up to the distance where $L=1$ and coarsened at greater distances.

Four scalar parameters fully describe a stretched grid: the size of the cubed sphere, the stretch factor $(S)$, the target latitude $\left(T_{\phi}\right)$, and the target longitude $\left(T_{\theta}\right)$. These concise parameters are conceptually simple, precise, and give the user nimble control of the grid. The combination of cubed-sphere size and stretch factor controls the grid resolution. The target latitude and longitude specify the center of the refined domain. Moderate stretch factors (e.g., 1.4-3.0) are suitable for broad refinements for continental-scale studies. Large stretch factors (e.g., > 5.0) are suitable for localized refinements for regional-scale studies.

\subsection{Choosing an appropriate stretch factor}

Although the stretch factor is a well-defined parameter, appropriate values for atmospheric chemistry simulations will be application-specific and moderately variable. For computational efficiency, it is desirable to use the largest viable stretch factor to achieve the finest refinement for a given cubed-sphere size. However, larger stretch factors also result in a smaller refinement and in coarser resolutions outside the refined domain. To determine the maximum suitable stretch factor for a given application, one should consider the size of the domain that should be refined and the sensitivity of the study species to coarse resolutions outside the refinement. A simple procedure for choosing a stretch factor, $S$, is choosing the maximum stretch factor subject to two constraints:

1. Constraining $S$ by the size of the refined domain. Local scaling is approximately constant and equal to $1 / S$ throughout the target face. Therefore, defining the re- 

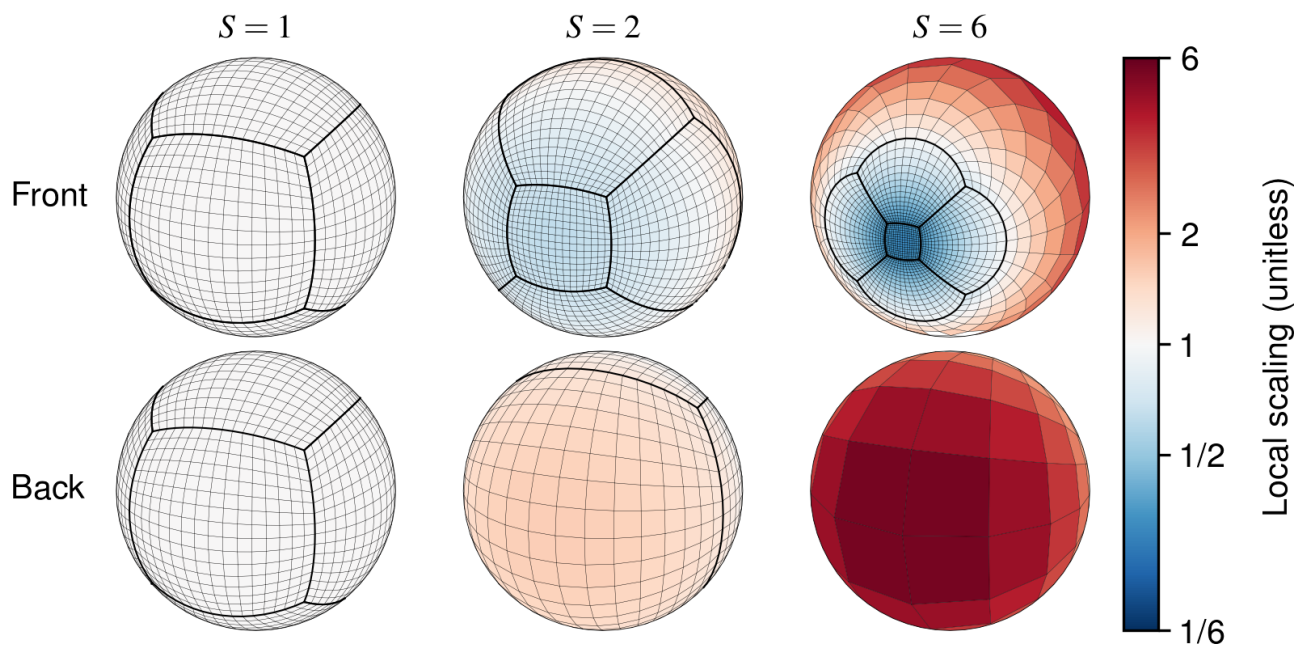

Figure 2. Three stretched grids that illustrate the effect of the stretch factor $(S)$ on stretching a $\mathrm{C} 16$ cubed sphere. Local scaling is the relative change to a grid box's edge length induced by stretching.

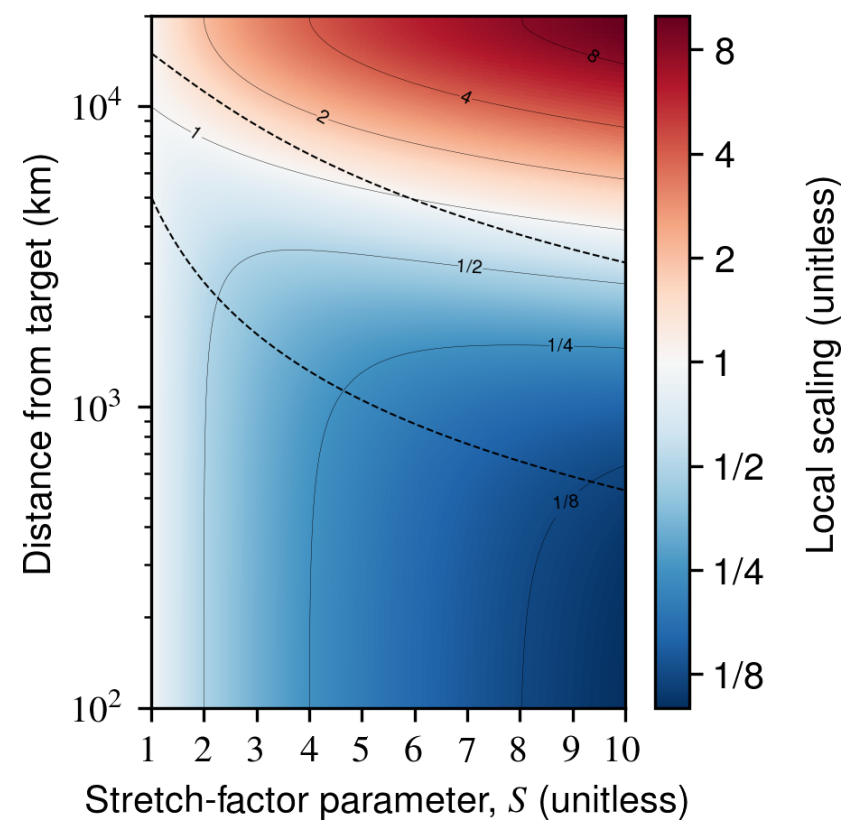

Figure 3. Local scaling as a function of distance from the target point, for stretch factors in the range 1-10. The dashed lines show the distance from the target point to the cubed-sphere face edges after stretching. The lower dashed line is the distance to the center of the target face's edges, and the upper dashed line is the distance to the center of the opposite face edges.

fined domain as the region where resolution is enhanced by a factor of $\sim S$, the target face is a reasonable approximation of the refined domain. For a target face with width greater than $w_{\mathrm{tf}}, S$ must satisfy

$S \leq 0.414 \cot \left(w_{\mathrm{tf}} / 4 r_{\mathrm{E}}\right)$, where $r_{\mathrm{E}}$ is Earth's radius. Here, we define target-face width, $\mathrm{w}_{\mathrm{tf}}$, as the edge-to-edge distance across the center of the face. For example, for a refined domain with a diameter of at least $3000 \mathrm{~km}$, the target face should be at least $3000 \mathrm{~km}$ wide, and thus the stretch factor should be less than or equal to 3.5. Alternatively, one could inspect Fig. 3 to find the distance from the target point to the edge of the target face for a given value of $S$.

2. Constraining $S$ by a maximum and minimum resolution. The target resolution is $S^{2}$ times finer than its antipode's resolution; therefore, a constraint for $S$ based on the desired maximum resolution, $R_{\max }$, and minimum resolution, $R_{\min }$, is

$S \leq \sqrt{R_{\max } / R_{\min }}$

The minimum resolution, $R_{\min }$, is an important consideration. $R_{\min }$ imposes a limit on the coarsest resolution outside of the refined domain. Therefore, the choice of an appropriately fine $R_{\min }$ can reduce potential bias in species in the coarse grid outside of the refined domain from affecting the study species in the refined domain. For example, for a maximum and minimum resolution comparable to C 360 and C24 cubed spheres, $S \leq 3.9$, or for a maximum and minimum resolution comparable to C360 and C48 cubed spheres, $S \leq 2.7$.

Once the constraints for $S$ are determined, one can choose $S$ and the grid size for their simulation. For example, for a stretched grid with a refined domain with a diameter greater than $3000 \mathrm{~km}$, a maximum resolution of C360, and a minimum resolution of $\mathrm{C} 24$, the constraints would be $S \leq 3.5$ and $S \leq 3.9$. To determine the grid size and stretch factor for a simulation from these constraints, first, assume $S=3.5$ as an initial value. For a maximum resolution comparable 
to a $\mathrm{C} 360$ grid with $S=3.5$, the grid size would be $\mathrm{C} 102.9$ $(360 / 3.5=102.9)$. Since the grid size must be an even integer, one should round up to $\mathrm{C} 104$ and choose $S=3.46$ $(360 / 104=3.46)$.

The single refinement and the expansion of grid boxes outside the refined domain are important limitations of gridstretching. The coarse grid outside the refined domain is susceptible to resolution-dependent biases in $\mathrm{O}_{3}$ and $\mathrm{CO}$ (Wild and Prather, 2006; Yan et al., 2014, 2016), which could influence the representation of chemical processes in the refined domain. Therefore, the choice of an appropriately fine minimum resolution is important $\left(R_{\min }\right.$ in constraint 2$)$. Generally, stretched-grid simulations are well suited for applications that are principally sensitive to emissions and physical processes in the refined domain. For example, stretched-grid simulations are well suited for regional studies of boundary layer concentrations of short-lived species. Applications such as evaluations of the global tropospheric $\mathrm{O}_{3}$ budget are better suited for standard cubed-sphere simulations.

\subsection{Model configuration}

The simulations in this paper use a shared model configuration of GCHP version 13.0.0-alpha.3. We use default emissions for all species. Table 2 summarizes the emission inventories that represent sources of $\mathrm{NO}_{x}$ in the simulations. Briefly, we use monthly anthropogenic emissions based on the National Emission Inventory (NEI) for 2011 with updated annual scaling factors to account for changes in annual totals since 2011. In 2019, the scaling factor for NO was 0.61. Biomass burning emissions are from the Global Fire Emissions Database version 4 (GFED4; van der Werf et al., 2017). Aircraft emissions are from the Aviation Emissions Inventory Code (AEIC; Stettler et al., 2011). We use inventories for $\mathrm{NO}_{x}$ emissions from soil microbial activity and lightning calculated offline at the native resolution of the meteorology (Weng et al., 2020; The International GEOS-Chem User Community, 2019). Offline soil $\mathrm{NO}_{x}$ emissions are based on the scheme described in Hudman et al. (2012), and offline lightning $\mathrm{NO}_{x}$ emissions are based on the scheme described in Murray et al. (2012). For meteorological data, we use GEOS-FP data because it offers superior horizontal resolution data for advection input variables $\left(0.25^{\circ} \times 0.3125^{\circ}\right)$. All simulations use a 10 min time step for chemistry and a 5 min time step for transport.

Simulations are named according to their grid. Standard cubed-sphere simulations are named by their resolution with the suffix "-global", referring to their resolution being quasiuniform globally. For example, a standard C180 cubedsphere simulation is named "C180-global". Stretched-grid simulations are named according to their refinement effective resolution, with a suffix denoting the region that is refined. For example, a stretched-grid simulation with an effective resolution of $\mathrm{C} 180$ in the contiguous US is named "C180e-US". "C180e" refers to the stretched-grid refinement being comparable to the resolution of a C180 cubed-sphere grid.

\subsection{Validating the stretched-grid capability}

Next, we test the implementation of stretched grid by comparing the concentrations of oxidants and $\mathrm{PM}_{2.5}$ from stretched-grid and cubed-sphere simulations. Prior tests were also conducted to identify and fix several technical errors in some component capabilities. We choose the contiguous US as the domain for this comparison and a standard C96 cubed-sphere simulation to serve as the control simulation (C96-global). The stretched-grid simulation, C96e-NA, has a grid size of C48 and stretching parameters $S=2.4$, $T_{\phi}=35^{\circ} \mathrm{N}$, and $T_{\theta}=96^{\circ} \mathrm{W}$. The target point was chosen so that the target face approximately encompassed the populous regions of North America. The stretch factor was chosen so that the average resolution of C96e-NA was equal to the average resolution of C96-global in the contiguous US; we note that the stretch factor is 2.4 , rather than 2.0 , because the US is a region where the standard cubed-sphere grid has a finer resolution than its global average, as shown in Appendix A. Figure 4 compares the resolution of C96e-NA and C96-global grids.

A consequence of the similar resolution of the C96-global and C94-global grids is that their grid boxes have little overlap; this makes their comparison sensitive to the precision of upscaling emissions (aliasing effects, i.e., differences in upscaled emissions like NO point sources from differences in how the grids cover a region). To calibrate an expectation for these differences, we compare C96-global to a second standard cubed-sphere simulation, C94-global. We choose $\mathrm{C} 94$-global because the similar resolution minimizes the frequency that its grid boxes overlap with the C96-global grid boxes. Therefore, the comparison of C94-global and C96-global isolates differences from aliasing effects. The frequency of grid box overlap between C96-global and C94-global is analogous to a beat frequency of 2; the regions where overlap occurs is near the edges and across the center lines of the faces.

Figure 5 compares C96e-NA with C96-global and C94-global with C96-global. These comparisons are for the fourth simulation month, to accommodate relaxation time for $\mathrm{CO}$ and $\mathrm{O}_{3}$ (the simulations started 1 June 2018 and ran through 1 October 2018). All three simulations used an identical model configuration, apart from the grid, which is described in Sect. 2.4. The scatter near the surface is caused by differences in the spatial allocation of emissions on different grids (the precision of upscaling). Figure 5 shows that simulated averages from C96e-NA are consistent with C96-global and that their differences are comparable to the differences between two similar cubed-sphere simulations. We note a small low bias in ozone above $400 \mathrm{hPa}$ associated with nonlinear chemical sensitivity to coarse grid boxes outside of the refined region. The C96e-NA grid resolution is coarser than 
Table 2. Emissions inventories in GEOS-Chem 13.0.0 that represent $\mathrm{NO}_{x}$ sources in the simulations conducted in this paper.

\begin{tabular}{llrl}
\hline Source type & Inventory & Resolution & Reference/notes \\
\hline Anthropogenic & & & \\
\hline \multicolumn{1}{c}{ US } & NEI-2011 & $0.1^{\circ} \times 0.1^{\circ}$ & Annual totals are updated for 2018/19 \\
Asia & MIX & $0.25^{\circ} \times 0.25^{\circ}$ & Li et al. (2017) \\
Global & CEDS $^{\mathrm{b}}$ & $0.5^{\circ} \times 0.5^{\circ}$ & McDuffie et al. (2020) \\
Lightning & - & $0.25^{\circ} \times 0.3125^{\circ}$ & Murray et al. (2012) \\
Soil & - & $0.25^{\circ} \times 0.3125^{\circ}$ & Weng et al. (2020) \\
Biomass burning & GFED4 & $0.25^{\circ} \times 0.25^{\circ}$ & van der Werf et al. (2017) \\
Aircraft & AEIC & $1.0^{\circ} \times 1.0^{\circ}$ & Stettler et al. (2011) \\
Shipping & CEDS & $0.5^{\circ} \times 0.5^{\circ}$ & McDuffie et al. (2020) \\
\hline
\end{tabular}

a Monthly fluxes, including diurnal and weekday-weekend variations and vertical allocations, based on criteria pollutants National Tier 1 from https://www.epa.gov/air-emissions-inventories/air-pollutant-emissions-trends-data (last access: 8 May 2020). ${ }^{\text {b }}$ Community Emissions Data System (CEDS)

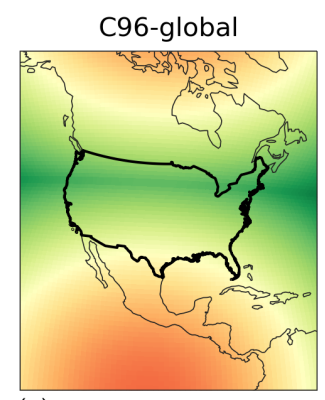

(a)

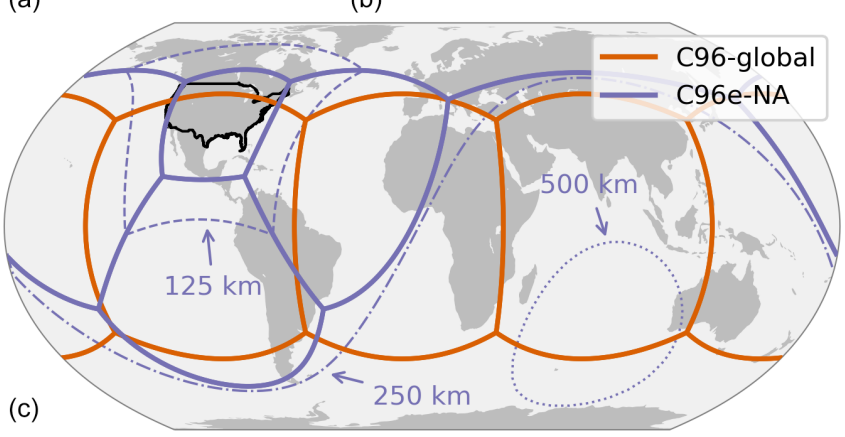

Figure 4. Comparison of C96-global and C96e-NA grids. The top panels show the variability of resolution for both grids. The bottom panel shows the grid face edges for C96-global and C96e-NA, with the 125,250 , and $500 \mathrm{~km}$ resolution contours for C96e-NA.

$250 \mathrm{~km}$ in most of Asia, while the C96-global grid is finer than $125 \mathrm{~km}$ (Fig. 4). A finer grid size or a smaller stretch factor could be used to increase resolution outside the refinement if this type of bias is of concern for a stretched-grid application.

\section{Stretched-grid case studies}

Next, we demonstrate stretched-grid simulations with GCHP by conducting case studies in Sect. 3.1 and 3.2. The applications we consider are regional comparisons of simulated tropospheric $\mathrm{NO}_{2}$ columns with observations. $\mathrm{NO}_{2}$ is chosen because it is a well-measured species, and the sensitivity of its simulated concentrations to model resolution and local chemical and physical processes make it a prime example of an application that is well suited for a stretched-grid simulation. Here we explore two of the primary reasons one might use the stretched-grid capability: (1) for a computationally efficient regional simulation and (2) to realize a finer resolution than is otherwise possible. Section 3.1 considers a comparison of columns in the contiguous US; columns are simulated at $\sim 50 \mathrm{~km}$ resolution, with stretched-grid and standard cubed-sphere simulations, to examine the ability of a stretched-grid simulation to produce similar results to a cubed-sphere simulation at a lesser computational expense. Section 3.2 experiments with the use of a very large stretch factor for a simulation targeting California with $\sim 10 \mathrm{~km}$ resolution and modest computational requirements.

We compare simulated tropospheric $\mathrm{NO}_{2}$ column densities to retrieved column densities from TROPOMI. TROPOMI is an instrument onboard the Sentinel-5P satellite launched in 2018 into a sun-synchronous orbit with a local overpass time of 13:30LST (local solar time). TROPOMI includes ultraviolet and visible band spectrometers. The retrieved $\mathrm{NO}_{2}$ column densities have $3.5 \times 5.5 \mathrm{~km}^{2}$ resolution and are calculated using a modified version of the Dutch OMI $\mathrm{NO}_{2}$ (DOMINO) retrieval algorithm (Boersma et al., 2011, 2018). We include observations with retrieved cloud fractions less than $10 \%$. Retrieved $\mathrm{NO}_{2}$ column densities are sensitive to the a priori profiles used to calculate the air mass factors (Boersma et al., 2018; Lorente et al., 2017). To avoid spurious differences from the retrieval a priori profiles when comparing simulated and retrieved $\mathrm{NO}_{2}$ column densities, we recalculate the air mass factors with the mean simulated relative vertical profiles (shape factors) from the stretched-grid simulations following the approach described in Cooper et al. (2020) and Palmer et al. (2001). Evaluations of TROPOMI $\mathrm{NO}_{2}$ columns show good correlation with ground-based measurements with a small low bias (Griffin 

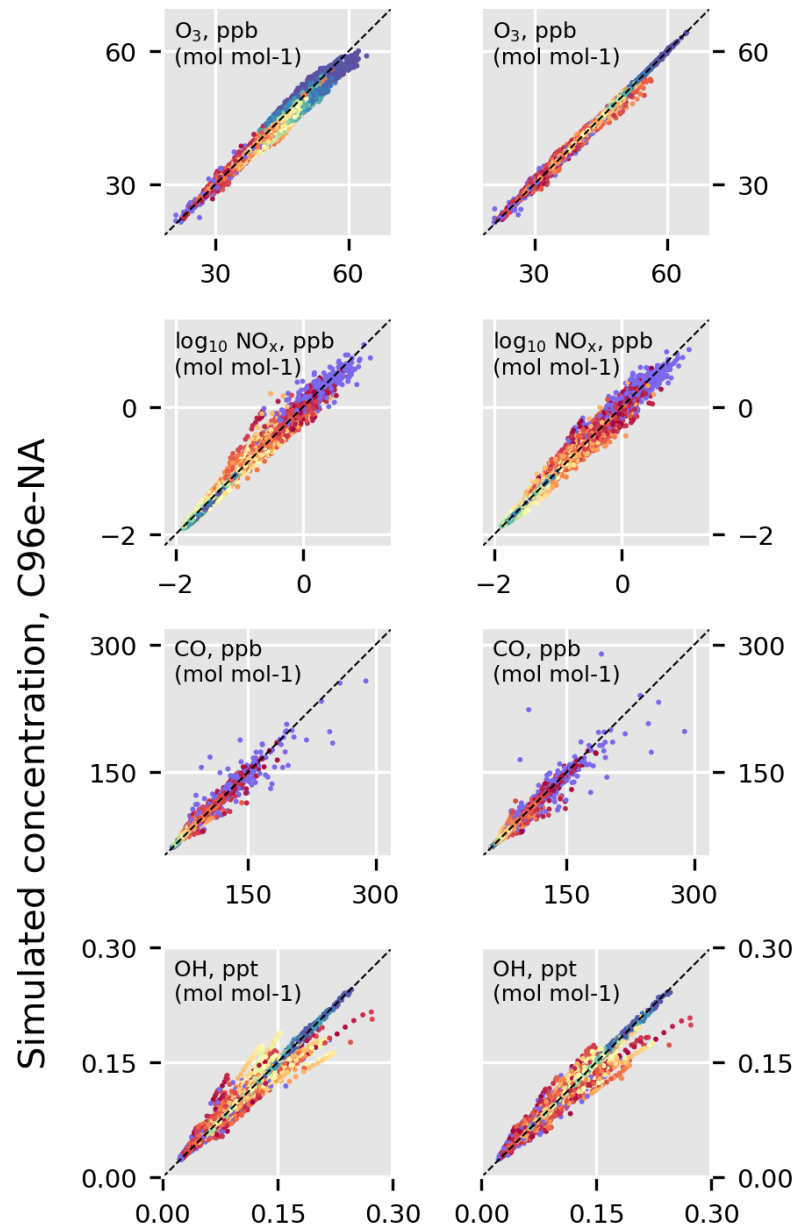

$-2$
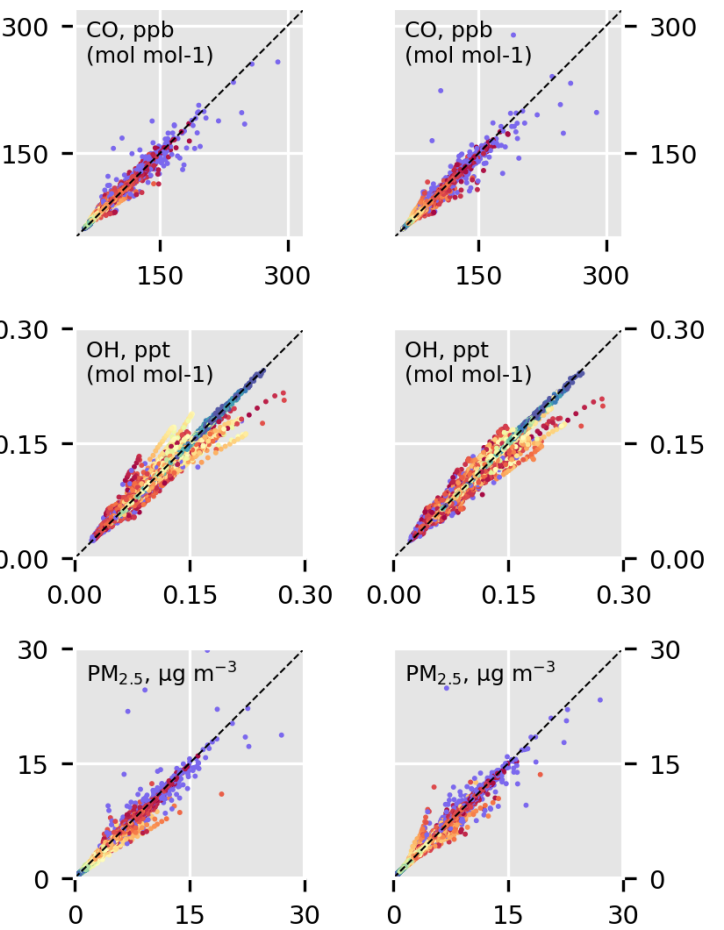

Simulated concentration, C96-global

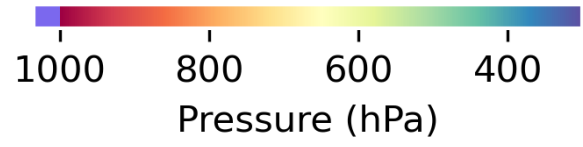

Figure 5. Comparison of simulated concentrations from C96e-NA with C96-global, and C94-global with C96-global. Points are 1month time averages for each grid box in the contiguous US for the fourth simulation month (September 2018). The right column gauges expected differences due to the precision of upscaling emissions to different grids. Concentrations in the lowermost model level are shown in purple.

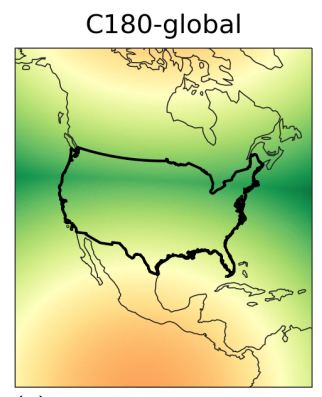

(a)

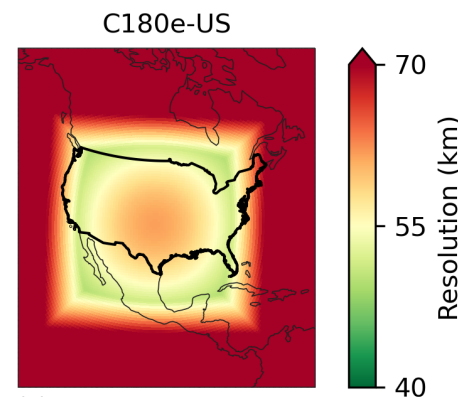

(b)
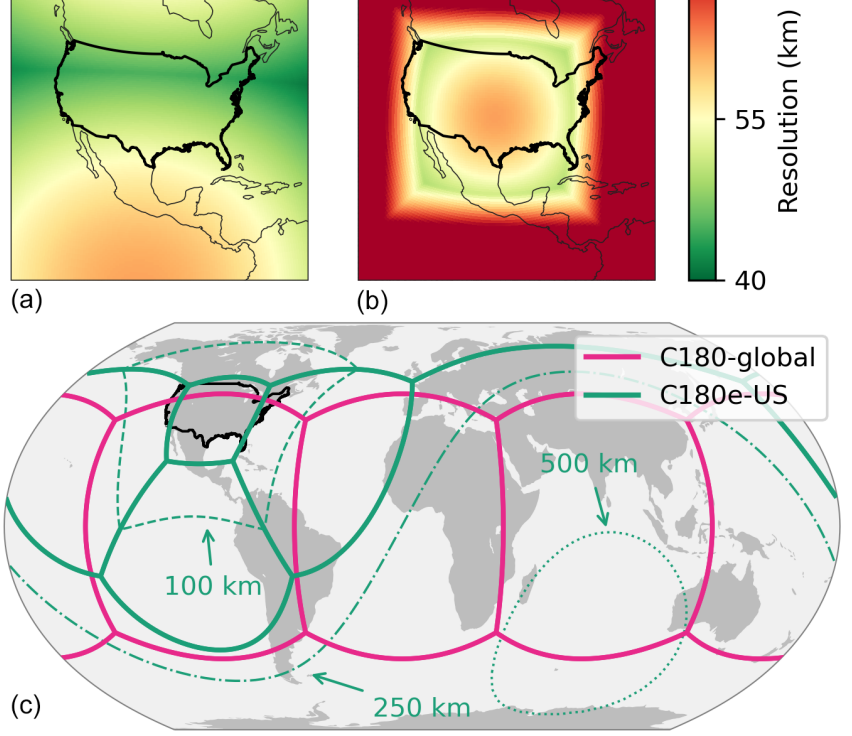

Figure 6. Comparison of C180-global and C180e-US grids. The top panels show the variability of resolution for both grids. The bottom panel shows the grid face edges for C180-global and C180e-US, with the 100,250 , and $500 \mathrm{~km}$ resolution contours for C180e-US.

et al., 2019; Ialongo et al., 2020; Zhao et al., 2020; Tack et al., 2021).

\subsection{A stretched-grid simulation with a moderate stretch factor}

Here we consider a comparison of simulated and observed $\mathrm{NO}_{2}$ columns in the contiguous US. We compare simulated columns with $\sim 50 \mathrm{~km}$ resolution from stretched-grid and standard cubed-sphere simulations with observations from TROPOMI. Our focus is on the technical ability to use a stretched grid for an efficient fine-resolution simulation of the columns compared to using a standard cubed sphere for this purpose. The contiguous US is a large refinement domain, and thus a moderate stretch factor is appropriate. This case is intended to be representative of a typical case where grid refinement is used in global models.

For the cubed-sphere simulation, we use a C180 grid and refer to it as $\mathrm{C} 180$-global. For the stretched-grid simulation, we use a stretch factor of $S=3.0$, a grid size of C60, and a target point at $36^{\circ} \mathrm{N}, 99^{\circ} \mathrm{W}$. We refer to the stretched-grid simulation as $\mathrm{C} 180 \mathrm{e}-\mathrm{US}$. The stretching parameters are chosen so that the target face approximately encompasses the contiguous US. Figure 6 shows the resolution of the two simulation grids. In the contiguous US, the average resolution of C180-global is $47.9 \mathrm{~km}$, and the average resolution of C180e-US is $56.6 \mathrm{~km}$. The total number of grid boxes in C180e-US is 9 times fewer than the number of grid boxes in C180-global (cf. C60 and C180 grids in Table 1). Both 


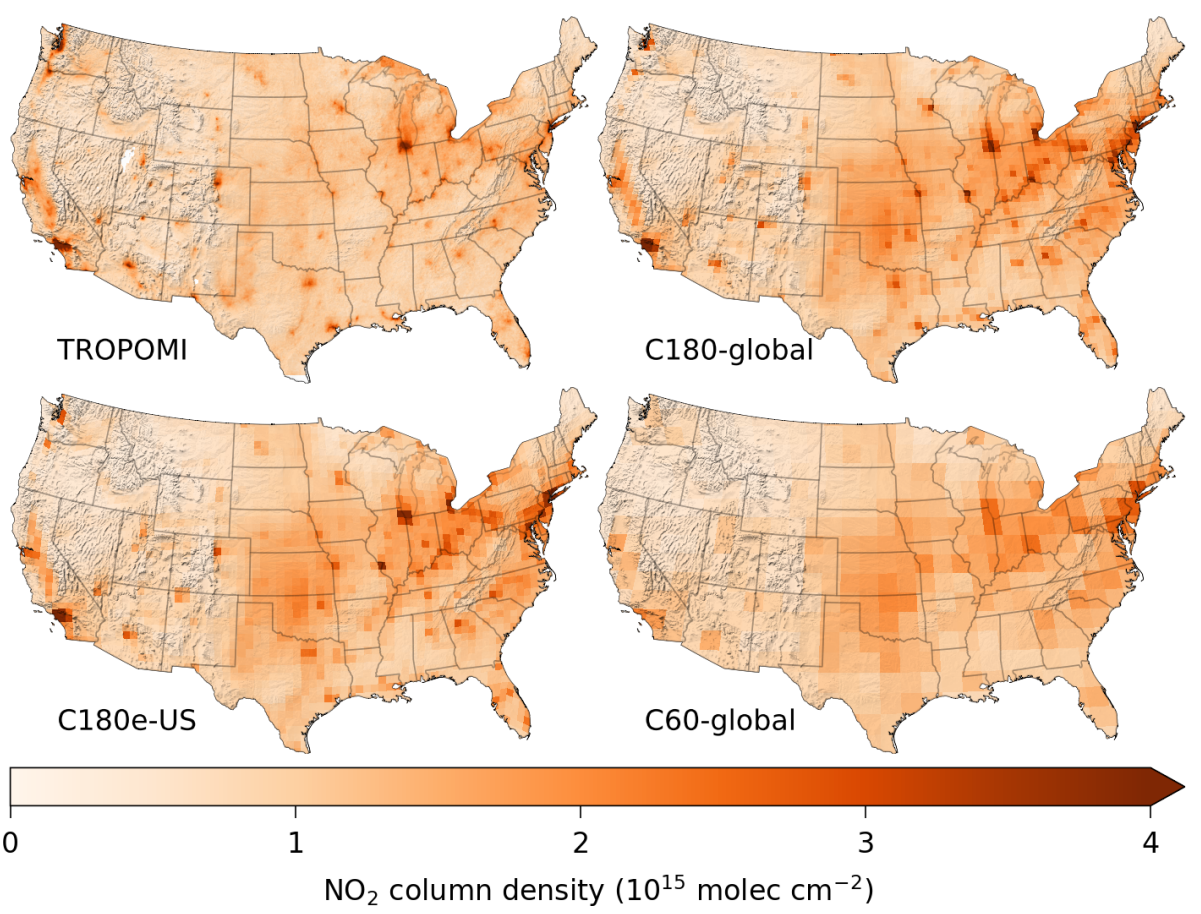

Figure 7. Mean tropospheric $\mathrm{NO}_{2}$ column densities from C180-global, C180e-US, C60-global, and TROPOMI observations for July 2019. Simulated means only include points where TROPOMI observations were available. TROPOMI columns shown here use shape factors from C180e-US. TROPOMI columns with shape factors from C180-global were nearly identical. An annotated map of the contiguous US is provided in Fig. C1.

simulations use an identical model configuration, apart from the grid. The model configuration is described in Sect. 2.4. To examine C180e-US without grid-stretching, we conduct a third simulation, C60-global.

Figure 7 shows tropospheric $\mathrm{NO}_{2}$ column densities from TROPOMI, C180-global, C180e-US, and C60-global for the US in July 2019. All three simulations included a 1-month spinup. An annotated map of the contiguous US is provided in Fig. C1. The TROPOMI columns have high $\mathrm{NO}_{2}$ concentrations over major cities and low $\mathrm{NO}_{2}$ concentrations in rural and remote regions. Simulated $\mathrm{NO}_{2}$ column densities from C180-global and C180e-US are consistent throughout the domain and generally capture the plumes over cities and the low concentrations in rural and remote areas. Small differences, like those seen near Four Corners and Denver, can be attributed to differences from upscaling the emissions to the simulation grids (i.e., aliasing). In the case of the differences near Four Corners, emissions from natural gas production and power plants in the region have a spatial scale that is finer than the simulation grids. C60-global failed to resolve the local enhancements over major cities; a comparison with C180e-US highlights the effectiveness of grid-stretching.

The computational demands of C180e-US were significantly less than C180-global and comparable to C60-global. Table 3 gives timing test results for C180-global, C180e-US, and C60-global. In terms of total computational workload, the total CPU time for C180e-US was $\sim 19$ times less than

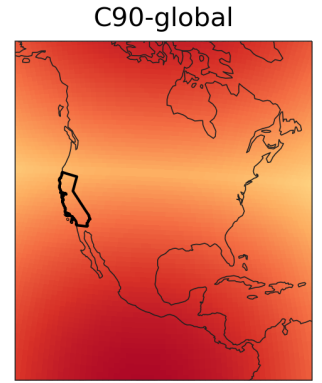

(a)

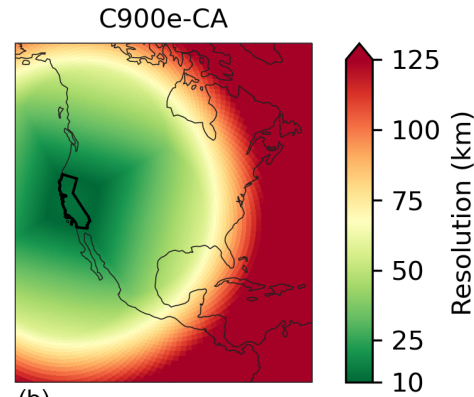

(b)

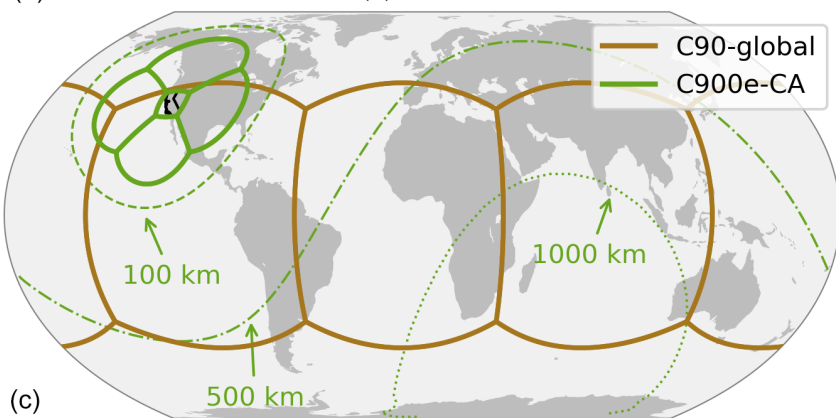

Figure 8. Comparison of C90-global and C900e-CA grids. The top panels show the variability of resolution for both grids. The bottom panel shows the grid face edges for $\mathrm{C} 90$-global and C900e-CA, with the 100,500 , and $1000 \mathrm{~km}$ resolution contours for C900e-CA. 
Table 3. The 2-week timing test results comparing the computational expense of C180-global, C180e-US, and C60-global.

\begin{tabular}{llrrr}
\hline & & C180-global & C180e-US & C60-global \\
\hline Number of cores used & (CPUs) & 384 & 48 & 48 \\
\hline Wall time & & & & \\
\hline \multicolumn{1}{c}{ Chemistry } & (hours) & 21.8 & 7.0 & 7.2 \\
Dynamics & (hours) & 3.1 & 1.7 & 1.7 \\
Data input & (hours) & 0.5 & 1.8 & 0.3 \\
Other & (hours) & 0.3 & 0.2 & 0.2 \\
\hline Total wall time & (hours) & 25.7 & 10.7 & 9.4 \\
\hline Total CPU time & (days) & 411 & 21.3 & 18.7 \\
Model throughput & (days/day) & 13.1 & 31.4 & 35.7 \\
\hline
\end{tabular}

* Simulation days per 24 wall hours.

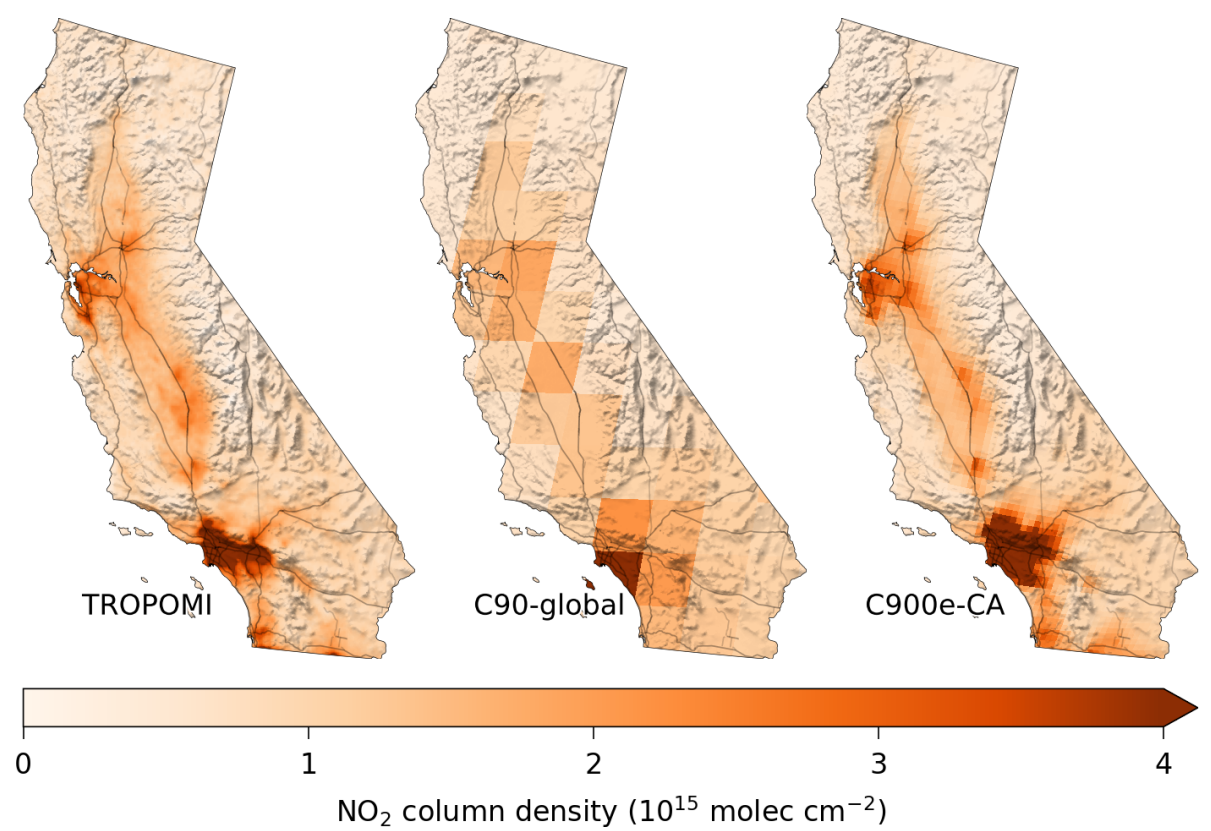

Figure 9. Mean tropospheric $\mathrm{NO}_{2}$ column densities from C90-global, C900e-CA, and TROPOMI observations for July 2019. Simulated means only include points where TROPOMI observations were available. TROPOMI columns shown here use shape factors from C900e-CA. An annotated map of California is provided in Fig. C2.

C180-global. The improvement is better than one would approximate by simply considering the reduction in the total number of grid boxes because the parallelization overhead is reduced as well. In terms of model throughput, C180e-US was 2.4 times faster than $\mathrm{C} 180$-global, despite using 8 times fewer cores. The total CPU time for C180e-US was $15 \%$ greater than C60-global. The slight increase of data input cost in C180e-US is suspected to be caused by a load imbalance in online input regridding in ESMF. Work to mitigate this load imbalance is underway.

\subsection{A stretched-grid simulation with a large stretch factor}

A large stretch factor creates a grid with a strong but localized refinement. Here, we experiment with using a large stretch factor to simulate $\mathrm{NO}_{2}$ columns in California at $\sim 10 \mathrm{~km}$ resolution. Simulated $\mathrm{NO}_{2}$ columns in California are known to be sensitive to model resolution because of significant variability in emissions and topography (Valin et al., 2011). This case study is intended to probe the computational ability for very fine simulations and the feasibility of using a highly stretched grid for an application that is well-suited for stretching. 
For the stretched-grid simulation, we choose a grid size of C90 with stretching parameters $S=10, T_{\phi}=37.2^{\circ} \mathrm{N}$, and $T_{\theta}=119.5^{\circ} \mathrm{W}$. We refer to this simulation as C900e-CA. The stretching parameters were chosen so that the target face approximately encompassed California. For comparison, we also conduct a cubed-sphere simulation with a C90 grid, which we refer to as C90-global. C90-global is effectively C900e-CA without grid-stretching. Both simulations use an identical model configuration, apart from the grid. Figure 8 compares the resolution of the two simulation grids. The average resolution of $\mathrm{C} 900 \mathrm{e}-\mathrm{CA}$ in California is $11.2 \mathrm{~km}$. To understand the variability of the $\mathrm{C} 900 \mathrm{e}-\mathrm{CA}$ grid resolution it is useful to consider the local scaling at various locations. For example, New York is approximately $4000 \mathrm{~km}$ from C900eCA's target point. Figure 3 shows that for $S=10$, the local scaling at $4000 \mathrm{~km}$ is close to 1 . Equivalently, substituting $S=10$ and $\Theta=4000 \mathrm{~km} / r_{\mathrm{E}}$ in Eq. (2) gives $L=1.04$. Therefore, the resolution of C900e-CA in New York is similar to a standard C90 cubed sphere. This can be confirmed in Fig. 8. The combination of a large stretch factor $(S=10)$ and moderate grid size (C90) causes some grid boxes to become very coarse. Grid boxes in the Indian Ocean and southeastern Africa are coarser than $1000 \mathrm{~km}$. These coarse grid boxes will result in an errors in $\mathrm{O}_{3}$ production and an overestimation of stratosphere-troposphere exchange (Wild and Prather, 2006). Therefore, the C900e-CA grid would not be suitable for applications sensitive to $\mathrm{O}_{3}$ or $\mathrm{CO}$ in the midtroposphere and upper troposphere. This underscores that selection of an appropriate stretched grid is application specific.

C900e-CA leverages the fine spatial resolution of anthropogenic NO emissions data available for the US; the NEI-2011 inventory has a $0.1^{\circ} \times 0.1^{\circ}$ grid $(\sim 9 \mathrm{~km})$. C900e-CA uses meteorological data from the GEOS-FP data product with a spatial resolution of $0.25^{\circ} \times 0.3125^{\circ}$ $(\sim 25 \mathrm{~km})$. We expect some of the detailed orographic and coastal effects in California to be missed. C900e-CA identifies a need for even finer resolution of meteorological data, for which there is ongoing work in the GCHP-GMAO community. In the regions where C900e-CA's grid is finer than the GEOS-FP data, the data are conservatively downscaled (online by ESMF). We evaluate the effect of using downscaled meteorological data on the simulated $\mathrm{NO}_{2}$ columns in Appendix D and find no significant ill effects for our application.

Figure 9 shows tropospheric $\mathrm{NO}_{2}$ column densities from TROPOMI, C900e-CA, and C90-global for California in July 2019. Both simulations used a 1-month spinup. An annotated map of California is provided in Fig. C2. The TROPOMI columns have significant fine-scale variability throughout California; high concentrations over Los Angeles and in the San Francisco Bay Area; and smaller highconcentration features over Sacramento, Fresno, and Bakersfield. C900e-CA resolves many of the fine-scale spatial features seen in the TROPOMI columns, including the small high-concentration features over Sacramento, Fresno, and Bakersfield. The coarse resolution of C90-global fails to resolve most spatial features seen in the TROPOMI and C900e-CA columns and significantly underestimates high concentrations, except in Los Angeles (LA). The underestimation of high concentrations in C90-global, such as in the San Francisco Bay Area, is associated with the averaging of fine-scale urban emissions over the coarse grid boxes. A subtle feature in the TROPOMI columns is the strong gradient along the LA Basin perimeter. Neither simulation captures this gradient well, and LA's plume spuriously spreads into the Mojave Desert. The shallow inversion that prevents the plume from rising over the mountains might be better represented in finer-resolution meteorological inputs that could better resolve coastal dynamics. Nonetheless, C900e-CA demonstrates a pronounced improvement over C90-global at resolving the challenging heterogeneity of California with similar computational expense (within 17\%).

\section{Conclusions}

Fine-resolution simulations of atmospheric chemistry are necessary to capture fine-scale modes of variability such as localized sources, nonlinear chemistry, and boundary layer processes, but fine-resolution simulations have been impeded by computational expense. This work developed stretched grids for the high-performance implementation of GEOS-Chem (GCHP). The capability was validated against global cubed-sphere simulations. Applications were probed with case studies that compared simulated concentrations with observations from the TROPOMI satellite instrument.

Stretched grids enable multiscale grids in GCHP while complementing the other multiscale grid methods that are available in GEOS-Chem implementations. A primary benefit of grid-stretching is ease of use. The refinement is flexible and controlled by four simple runtime parameters. Stretched grids operate naturally in GCHP, so switching between a stretched grid and cubed-sphere grid is seamless. Stretchedgrid simulations are stand-alone simulations that do not require any pregenerated or dynamically coupled boundary conditions. Compared to nested grids, the main disadvantages of grid-stretching are that there is a single refinement and that one cannot control the refined domain, refinement resolution, and global resolution independently.

Stretched-grid simulations can be used for regional- or continental-scale simulation purposes. Generally, stretch factors in the range 1.4-4.0 are applicable for large refined domains. Higher stretch factors can be used for simulations at very fine resolution for regional-scale applications. To aid in choosing an appropriate stretch factor, we propose a simple procedure based on choosing the maximum stretch factor subject to two constraints: the size of the refined domain and the maximum and minimum resolution. 
Computationally, stretched-grid simulations are capable of unprecedented spatial resolutions for GEOS-Chem. Finescale emissions, with accurate spatial and temporal variability, and meteorological inputs with fine horizontal, temporal, and vertical resolution are needed to fully exploit these newly achievable resolutions. Stretched grids are publicly available and ready for scientific application in GEOS-Chem version 13.0.0.

\section{Appendix A: Variability of cubed-sphere grid resolution}

Figure A1 shows the variability of a C180 cubed-sphere grid's resolution. The coarsest resolutions are at the center of faces, and the finest resolutions are at the corners of the faces. The average resolution of a cubed-sphere grid can be approximated by $\sqrt{A_{\mathrm{E}} /(6 \times N \times N)}$, where $A_{\mathrm{E}}$ is the surface area of Earth $\left(\sim 510 \times 10^{6} \mathrm{~km}^{2}\right)$ and $N$ is the size of the cubed sphere (e.g., $N=180$ for a C180 grid). The average resolution of a C180 grid is $51 \mathrm{~km}$. The resolution at the center of the face is $62 \mathrm{~km}$, and the resolution at the corner of the face is $41 \mathrm{~km}$.

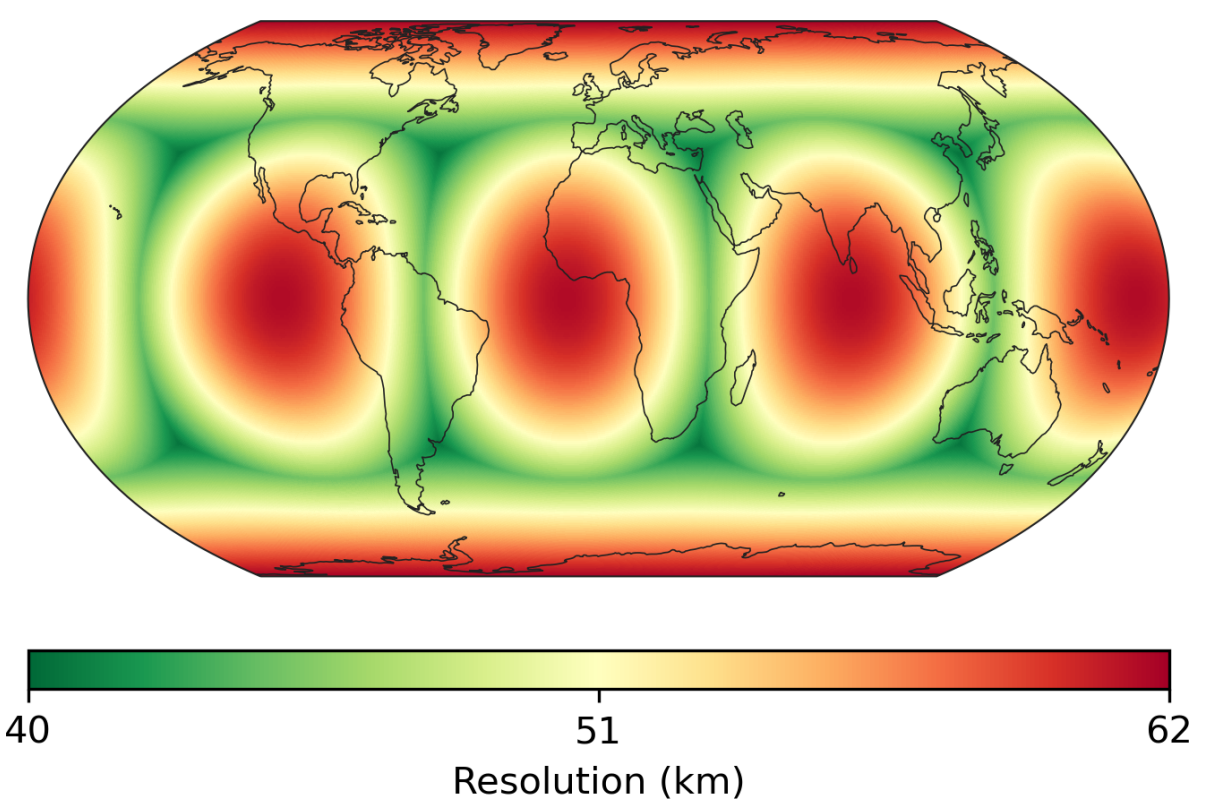

Figure A1. Variability of a C180 cubed sphere's resolution. 


\section{Appendix B: Derivation of local scaling}

Local scaling, $L$, is the relative change to a grid box's length from grid stretching. Consider a line segment that follows a meridian. The line segment starts at $y$ and has length $\Delta y$. After remapping the line segment with the Schmidt transform (Eq. 1), the line segment starts at $y^{\prime}$ and has length $\Delta y^{\prime}$. The limit of the segment's local scaling as $\Delta y \rightarrow 0$ is equal to the derivative of the Schmidt transform:

$$
\begin{aligned}
L\left(y^{\prime} ; S\right)= & \lim _{\Delta y \rightarrow 0} \frac{\Delta y^{\prime}}{\Delta y}=\lim _{\Delta y \rightarrow 0} \frac{\phi^{\prime}(y+\Delta y)-\phi^{\prime}(y)}{\Delta y} \\
& =\frac{\mathrm{d}}{\mathrm{d} y} \phi^{\prime}(y) .
\end{aligned}
$$

The derivative of the Schmidt transform is

$$
\frac{\mathrm{d}}{\mathrm{d} y} \phi^{\prime}(y)=\frac{2 S}{S^{2}(1-\sin y)+\sin y+1},
$$

and thus the local scaling at $y^{\prime}$ is

$L\left(y^{\prime} ; S\right)=\frac{2 S}{S^{2}(1-\sin y)+\sin y+1}$.

We can obtain the local scaling at $y$, rather than $y^{\prime}$, by substituting the inverse of the Schmidt transform into Eq. (B3). This gives

$L(y ; S)=\frac{S^{2}(1+\sin y)-\sin y+1}{2 S}$.

Finally, we can generalize Eq. (B4) so it is a function of arclength from the target. The center of the refinement after applying Eq. (1) is at the South Pole. The arclength from $y$ to the South Pole is $\Theta=y-(-\pi / 2)$. Substituting $y=\Theta-\pi / 2$ into Eq. (B4) gives

$L(\Theta ; S)=\frac{S^{2}(1-\cos \Theta)+\cos \Theta+1}{2 S}$. 


\section{Appendix C: Maps of locations discussed in the text}

Figure $\mathrm{C} 1$ shows a map of the contiguous US. Locations that are discussed in the text and locations with notable features in Fig. 7 are marked. Figure C2 shows a map of California. Locations that are discussed in the text and locations with notable features in Fig. 9 are marked.

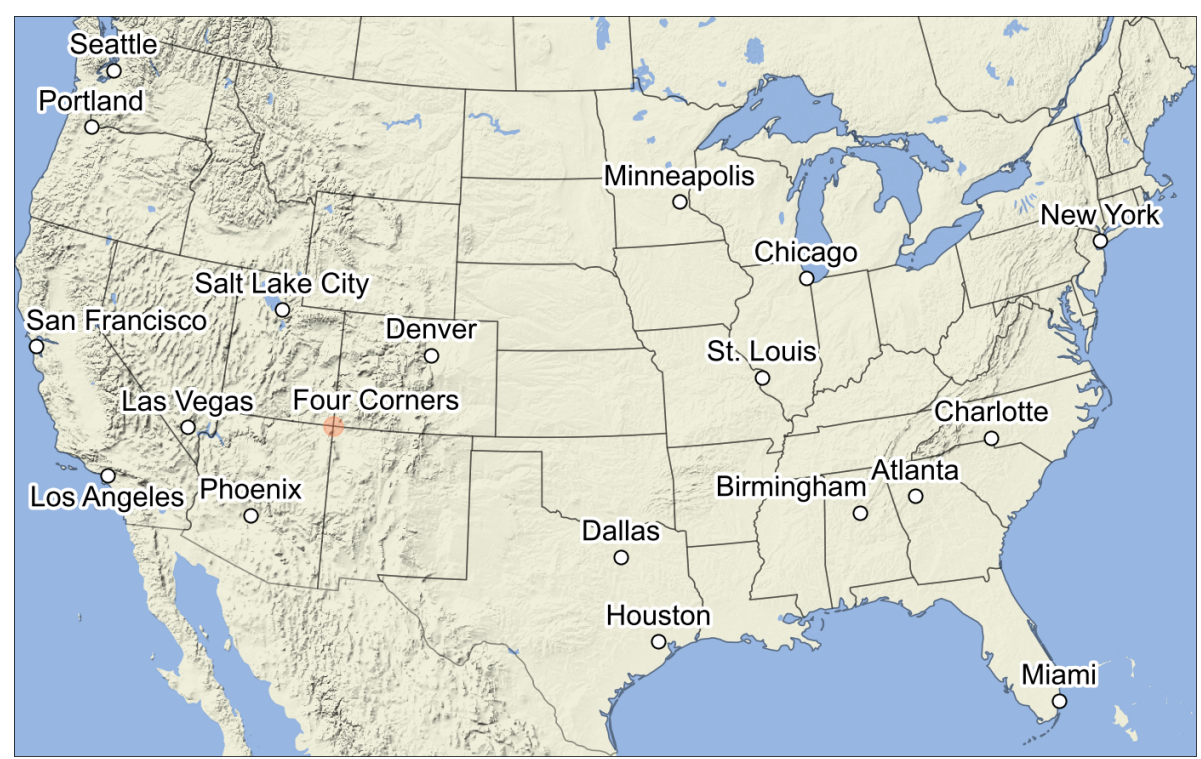

Figure C1. Map of the contiguous US. Locations discussed in the text and locations with notable features in Fig. 7 are marked. 


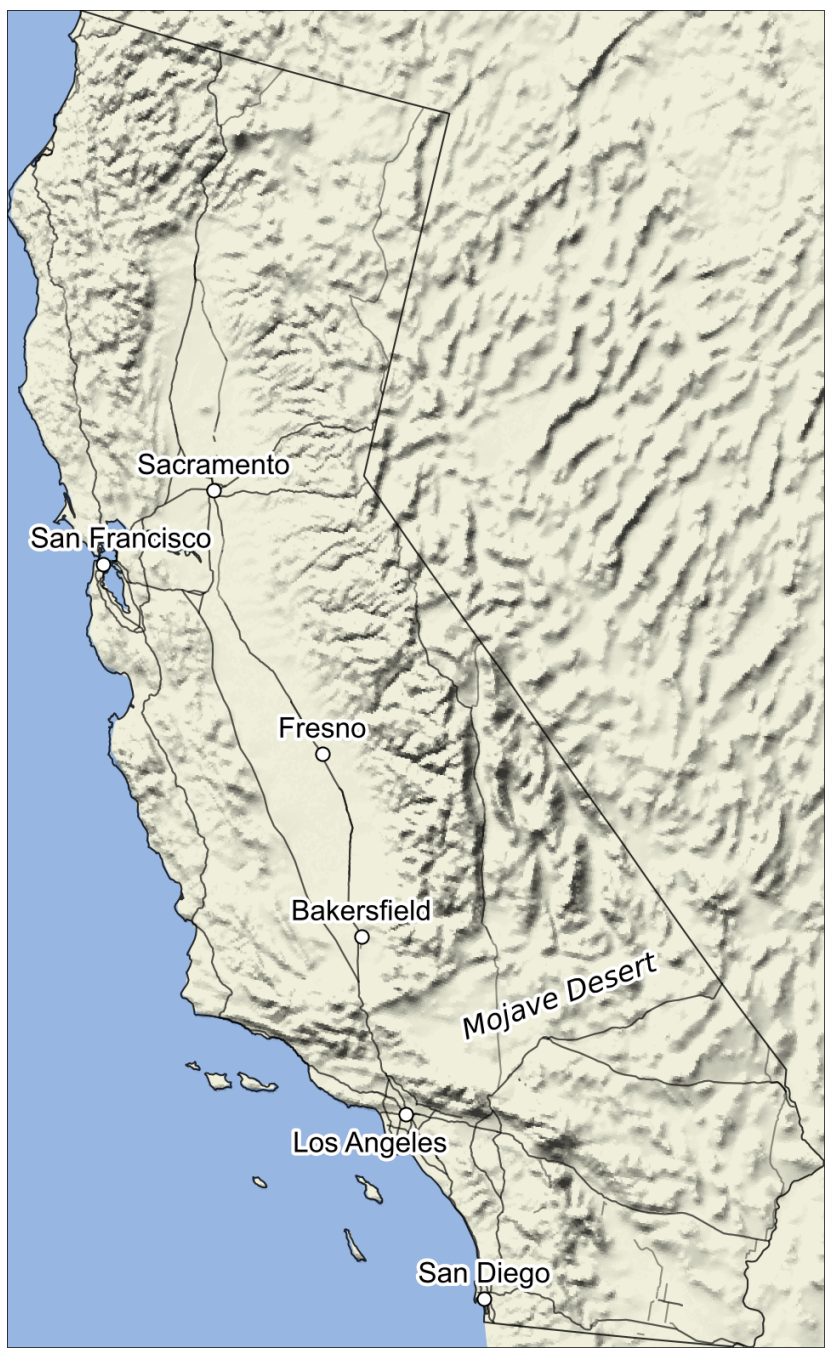

Figure C2. Map of the California. Locations discussed in the text and locations with notable features in Fig. 9 are marked. 
Appendix D: Evaluation of interpolating meteorological inputs in California $\mathrm{NO}_{2}$ simulation

Section 3.2 demonstrates the use of a stretched-grid simulation for simulating tropospheric $\mathrm{NO}_{2}$ column densities in California. The simulation, C900e-CA, has an average resolution of $11.2 \mathrm{~km}$ in California, which is approximately twice as fine as the input meteorological data $\left(0.25^{\circ} \times 0.3125^{\circ}\right.$ grid, or $\sim 25 \mathrm{~km}$ resolution). To check that interpolating meteorological data in C900e-CA does not have significant unexpected consequences, we downscaled the data to a $0.5^{\circ} \times 0.625^{\circ}$ grid $(\sim 50 \mathrm{~km})$ and conducted a pair of stretched-grid simulations with $\sim 25 \mathrm{~km}$ resolution; one used the $0.25^{\circ} \times 0.3125^{\circ}$ data, and the other used the downscaled $0.5^{\circ} \times 0.625^{\circ}$ data. The $\mathrm{NO}_{2}$ columns from these simulations are shown in Fig. D1 (second row), along with the columns from TROPOMI and C900e-CA (first row). The grid for these simulations was a C60 cubed sphere with a stretch factor of $S=6(\sim 25 \mathrm{~km})$ and a target point of $37.2^{\circ} \mathrm{N}$, $119.5^{\circ} \mathrm{W}$ (same as C900e-CA). Both used a 1-month spinup. Comparison of the lower panels in Fig. D1 shows that interpolating the $0.5^{\circ} \times 0.625^{\circ}$ meteorological inputs to the $\sim 25 \mathrm{~km}$ grid has little effect on the simulated $\mathrm{NO}_{2}$ columns. This suggests the consequences of interpolating meteorological data in C900e-CA are minor for our application and that the variability is driven by the resolution of emissions data ( $\sim 9 \mathrm{~km}$ resolution). 

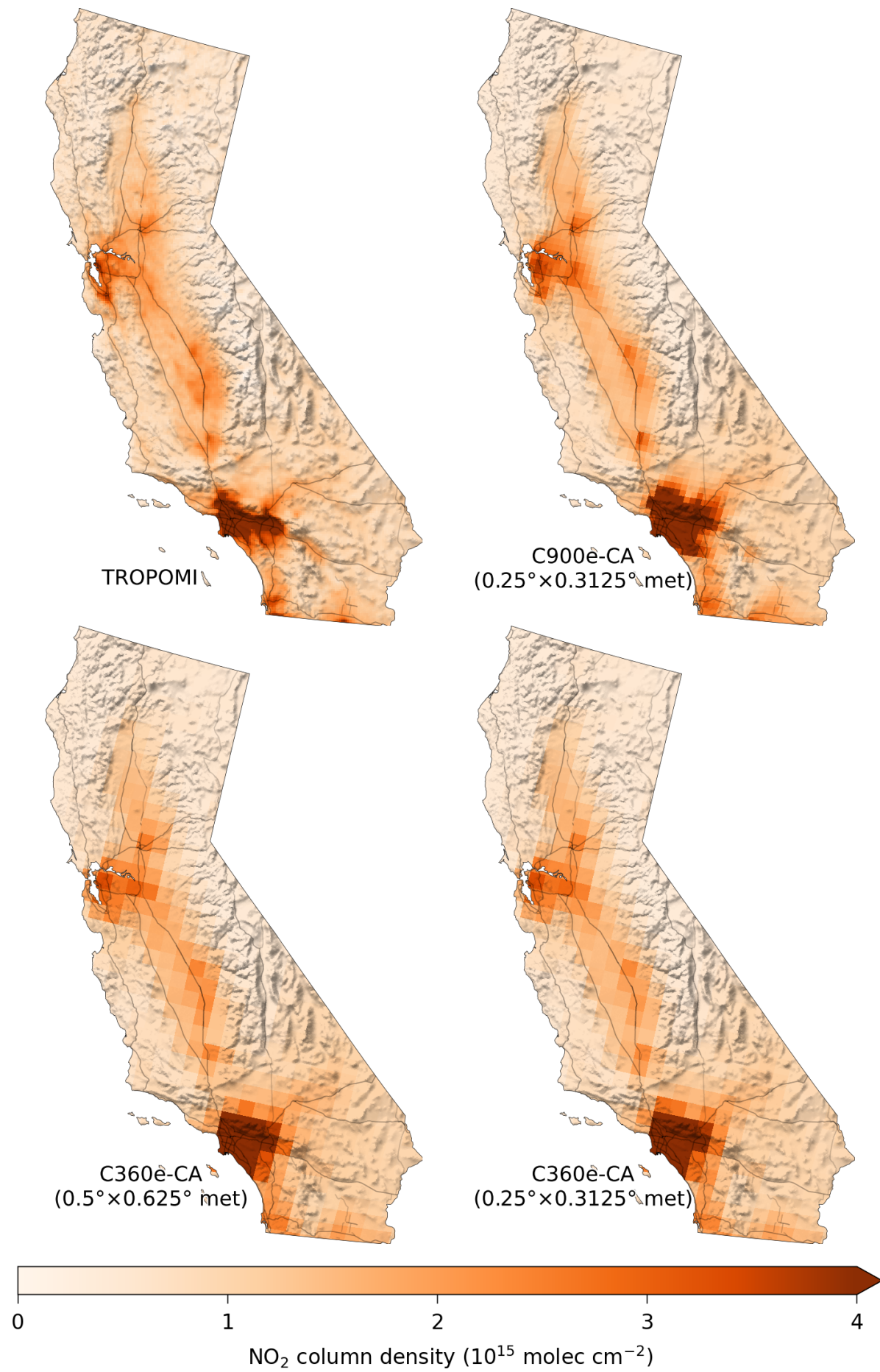

Figure D1. Mean tropospheric $\mathrm{NO}_{2}$ column densities from TROPOMI, C900e-CA, C360e-CA with $0.25^{\circ} \times 0.3125^{\circ}$ meteorological data, and C360e-CA with meteorological data downscaled to $0.5^{\circ} \times 0.625^{\circ}$. 
Code availability. GEOS-Chem is an open source project distributed under the MIT License at https://github.com/geoschem/ GCHP (last access: 28 June 2021). The exact version of GCHP used in this paper was 13.0.0-alpha.3 and is archived on Zenodo (https://doi.org/10.5281/zenodo.4317978, The International GEOSChem User Community, 2020).

Data availability. The simulations in this paper use default GEOSChem 13.0 emissions and meteorological data that can be obtained from the GEOS-Chem input data repository: http://geoschemdata. wustl.edu/ExtData/ (last access: 4 October 2021). The instructions for downloading the input data for GEOS-Chem 13.0 from the data repository are given in the GEOS-Chem 13.0 User Guide (https: //gchp.readthedocs.io, last access: 8 October 2021).

Author contributions. LB implemented and validated the stretchedgrid capability in GCHP. RVM, DJJ, and SP provided project oversight and top-level design. MJC reprocessed TROPOMI columns with shape factors from simulations. EWL, LB, and SDE performed MAPL 2 upgrade in GCHP. BMA and TLC developed stretchedgrid capability in MAPL 2. WMP developed FV3. HW, JL, LTM, and JM developed grid-independent emissions for GEOS-Chem, and CAK developed HEMCO. LB wrote the manuscript. All authors contributed to manuscript editing and revisions.

Competing interests. The authors declare that they have no conflict of interest.

Disclaimer. Publisher's note: Copernicus Publications remains neutral with regard to jurisdictional claims in published maps and institutional affiliations.

Acknowledgements. We are grateful to the Research Infrastructure Service (RIS) at Washington University in St. Louis for providing computing resources. The meteorological data (GEOS-FP) used in this study have been provided by the Global Modeling and Assimilation Office (GMAO) at NASA Goddard Space Flight Center. We thank the two anonymous reviewers for their constructive comments and suggestions.

Financial support. This research has been supported by the Earth Sciences Division (grant no. AIST-18-0011) and the Natural Sciences and Engineering Research Council of Canada (grant no. RGPIN-2019-04670).

Review statement. This paper was edited by Fiona O'Connor and reviewed by two anonymous referees.

\section{References}

Allen, D., Pickering, K., Stenchikov, G., Thompson, A., and Kondo, Y.: A three-dimensional total odd nitrogen ( $\mathrm{NO} y$ ) simulation during SONEX using a stretched-grid chemical transport model, J. Geophys. Res.-Atmos., 105, 3851-3876, 2000.

Bey, I., Jacob, D. J., Yantosca, R. M., Logan, J. A., Field, B. D., Fiore, A. M., Li, Q., Liu, H. Y., Mickley, L. J., and Schultz, M. G.: Global modeling of tropospheric chemistry with assimilated meteorology: Model description and evaluation, J. Geophys. Res.-Atmos., 106, 23073-23095, https://doi.org/10.1029/2001JD000807, 2001.

Boersma, K., Braak, R., and van der A, R. J.: Dutch OMI NO2 (DOMINO) data product v2. 0, Tropospheric Emissions Monitoring Internet Service on-line documentation, available at: http://www.temis.nl/docs/OMI_NO2_HE5_2.0_2011. pdf (last access: 5 July 2020), 2011.

Boersma, K. F., Eskes, H. J., Richter, A., De Smedt, I., Lorente, A., Beirle, S., van Geffen, J. H. G. M., Zara, M., Peters, E., Van Roozendael, M., Wagner, T., Maasakkers, J. D., van der A, R. J., Nightingale, J., De Rudder, A., Irie, H., Pinardi, G., Lambert, J.-C., and Compernolle, S. C.: Improving algorithms and uncertainty estimates for satellite $\mathrm{NO}_{2}$ retrievals: results from the quality assurance for the essential climate variables (QA4ECV) project, Atmos. Meas. Tech., 11, 6651-6678, https://doi.org/10.5194/amt-11-6651-2018, 2018.

Cooper, M. J., Martin, R. V., McLinden, C. A., and Brook, J. R.: Inferring ground-level nitrogen dioxide concentrations at fine spatial resolution applied to the TROPOMI satellite instrument, Environ. Res. Lett., 15, 104013, https://doi.org/10.1088/17489326/aba3a5, 2020.

Courtier, P. and Geleyn, J.-F.: A global numerical weather prediction model with variable resolution: Application to the shallowwater equations, Q. J. Roy. Meteor. Soc., 114, 1321-1346, 1988.

Davis, D. D., Grodzinsky, G., Kasibhatla, P., Crawford, J., Chen, G., Liu, S., Bandy, A., Thornton, D., Guan, H., and Sandholm, S.: Impact of ship emissions on marine boundary layer $\mathrm{NO}_{\mathrm{x}}$ and $\mathrm{SO}_{2}$ Distributions over the Pacific Basin, Geophys. Res. Lett., 28, 235-238, https://doi.org/10.1029/2000GL012013, 2001.

Eastham, S. D., Weisenstein, D. K., and Barrett, S. R.: Development and evaluation of the unified troposphericstratospheric chemistry extension (UCX) for the global chemistry-transport model GEOS-Chem, Atmos. Environ., 89, 52-63, https://doi.org/10.1016/j.atmosenv.2014.02.001, 2014.

Eastham, S. D., Long, M. S., Keller, C. A., Lundgren, E., Yantosca, R. M., Zhuang, J., Li, C., Lee, C. J., Yannetti, M., Auer, B. M., Clune, T. L., Kouatchou, J., Putman, W. M., Thompson, M. A., Trayanov, A. L., Molod, A. M., Martin, R. V., and Jacob, D. J.: GEOS-Chem High Performance (GCHP v11-02c): a next-generation implementation of the GEOS-Chem chemical transport model for massively parallel applications, Geosci. Model Dev., 11, 2941-2953, https://doi.org/10.5194/gmd-112941-2018, 2018.

Feng, X., Lin, H., and Fu, T.-M.: WRF-GC: online two-way coupling of WRF and GEOS-Chem for regional atmospheric chemistry modeling, EGU General Assembly 2020, Online, 4-8 May 2020, EGU2020-5165, https://doi.org/10.5194/egusphereegu2020-5165, 2020

Fox-Rabinovitz, M., Côté, J., Dugas, B., Déqué, M., and McGregor, J. L.: Variable resolution general circulation models: Stretched- 
grid model intercomparison project (SGMIP), J. Geophys. Res., 111, D16104, https://doi.org/10.1029/2005JD006520, 2006.

Fox-Rabinovitz, M., Cote, J., Dugas, B., Deque, M., McGregor, J. L., and Belochitski, A.: Stretched-grid Model Intercomparison Project: decadal regional climate simulations with enhanced variable and uniform-resolution GCMs, Meteorol. Atmos. Phys., 100, 159-178, https://doi.org/10.1007/s00703-0080301-z, 2008.

Freitas, S. R., Longo, K. M., Chatfield, R., Latham, D., Silva Dias, M. A. F., Andreae, M. O., Prins, E., Santos, J. C., Gielow, R., and Carvalho Jr., J. A.: Including the sub-grid scale plume rise of vegetation fires in low resolution atmospheric transport models, Atmos. Chem. Phys., 7, 3385-3398, https://doi.org/10.5194/acp7-3385-2007, 2007.

Garcia-Menendez, F. and Odman, M. T.: Adaptive grid use in air quality modeling, Atmosphere, 2, 484-509, 2011.

Garcia-Menendez, F., Yano, A., Hu, Y., and Odman, M. T.: An adaptive grid version of CMAQ for improving the resolution of plumes, Atmos. Pollut. Res., 1, 239-249, 2010.

Goldberg, D. L., Lamsal, L. N., Loughner, C. P., Swartz, W. H., Lu, Z., and Streets, D. G.: A high-resolution and observationally constrained OMI NO2 satellite retrieval, Atmos. Chem. Phys., 17, 11403-11421, https://doi.org/10.5194/acp-17-114032017, 2017.

Goto, D., Dai, T., Satoh, M., Tomita, H., Uchida, J., Misawa, S., Inoue, T., Tsuruta, H., Ueda, K., Ng, C. F. S., Takami, A., Sugimoto, N., Shimizu, A., Ohara, T., and Nakajima, T.: Application of a global nonhydrostatic model with a stretched-grid system to regional aerosol simulations around Japan, Geosci. Model Dev., 8, 235-259, https://doi.org/10.5194/gmd-8-235-2015, 2015.

Griffin, D., Zhao, X., McLinden, C. A., Boersma, F., Bourassa, A., Dammers, E., Degenstein, D., Eskes, H., Fehr, L., Fioletov, V., Hayden, K., Kharol, S. K., Li, S., Makar, P., Martin, R. V., Mihele, C., Mittermeier, R. L., Krotkov, N., Sneep, M., Lamsal, L. N., Linden, M. t., Geffen, J. v., Veefkind, P., and Wolde, M.: High-Resolution Mapping of Nitrogen Dioxide With TROPOMI: First Results and Validation Over the Canadian Oil Sands, Geophys. Res. Lett., 46, 1049-1060, https://doi.org/10.1029/2018GL081095, 2019.

Harris, L. M., Lin, S.-J., and Tu, C.: High-Resolution Climate Simulations Using GFDL HiRAM with a Stretched Global Grid, J. Climate, 29, 4293-4314, https://doi.org/10.1175/JCLI-D-150389.1, 2016.

Heckel, A., Kim, S.-W., Frost, G. J., Richter, A., Trainer, M., and Burrows, J. P.: Influence of low spatial resolution a priori data on tropospheric NO2 satellite retrievals, Atmos. Meas. Tech., 4, 1805-1820, https://doi.org/10.5194/amt-4-1805-2011, 2011.

Hill, C., DeLuca, C., Balaji, Suarez, M., and Da Silva, A.: The Architecture of the Earth System Modeling Framework, Comput. Sci. Eng., 6, 18-28, https://doi.org/10.1109/MCISE.2004.1255817, 2004.

Hudman, R. C., Moore, N. E., Mebust, A. K., Martin, R. V., Russell, A. R., Valin, L. C., and Cohen, R. C.: Steps towards a mechanistic model of global soil nitric oxide emissions: implementation and space based-constraints, Atmos. Chem. Phys., 12, 7779-7795, https://doi.org/10.5194/acp-12-7779-2012, 2012.

Ialongo, I., Virta, H., Eskes, H., Hovila, J., and Douros, J.: Comparison of TROPOMI/Sentinel-5 Precursor $\mathrm{NO}_{2}$ observations with ground-based measurements in Helsinki, Atmos. Meas. Tech., 13, 205-218, https://doi.org/10.5194/amt-13-205-2020, 2020.

Keller, C. A., Long, M. S., Yantosca, R. M., Da Silva, A. M., Pawson, S., and Jacob, D. J.: HEMCO v1.0: a versatile, ESMF-compliant component for calculating emissions in atmospheric models, Geosci. Model Dev., 7, 1409-1417, https://doi.org/10.5194/gmd-7-1409-2014, 2014.

Kim, S.-W., Natraj, V., Lee, S., Kwon, H.-A., Park, R., de Gouw, J., Frost, G., Kim, J., Stutz, J., Trainer, M., Tsai, C., and Warneke, C.: Impact of high-resolution a priori profiles on satellite-based formaldehyde retrievals, Atmos. Chem. Phys., 18, 7639-7655, https://doi.org/10.5194/acp-18-7639-2018, 2018.

Krinner, G., Genthon, C., Li, Z.-X., and Le Van, P.: Studies of the Antarctic climate with a stretched-grid general circulation model, J. Geophys. Res.-Atmos., 102, 13731-13745, 1997.

Krol, M., Houweling, S., Bregman, B., van den Broek, M., Segers, A., van Velthoven, P., Peters, W., Dentener, F., and Bergamaschi, P.: The two-way nested global chemistry-transport zoom model TM5: algorithm and applications, Atmos. Chem. Phys., 5, $417-$ 432, https://doi.org/10.5194/acp-5-417-2005, 2005.

Li, J., Wang, Y., and Qu, H.: Dependence of Summertime Surface Ozone on $\mathrm{NO}_{x}$ and VOC Emissions Over the United States: Peak Time and Value, Geophys. Res. Lett., 46, 3540-3550, https://doi.org/10.1029/2018GL081823, 2019.

Li, M., Zhang, Q., Kurokawa, J.-I., Woo, J.-H., He, K., Lu, Z., Ohara, T., Song, Y., Streets, D. G., Carmichael, G. R., Cheng, Y., Hong, C., Huo, H., Jiang, X., Kang, S., Liu, F., Su, H., and Zheng, B.: MIX: a mosaic Asian anthropogenic emission inventory under the international collaboration framework of the MICS-Asia and HTAP, Atmos. Chem. Phys., 17, 935-963, https://doi.org/10.5194/acp-17-935-2017, 2017.

Li, Y., Henze, D. K., Jack, D., and Kinney, P. L.: The influence of air quality model resolution on health impact assessment for fine particulate matter and its components, Air Qual. Atmos. Hlth., 9, 51-68, https://doi.org/10.1007/s11869-015-0321-z, 2016.

Li, Y., Pickering, K. E., Barth, M. C., Bela, M. M., Cummings, K. A., and Allen, D. J.: Evaluation of Parameterized Convective Transport of Trace Gases in Simulation of Storms Observed During the DC3 Field Campaign, J. Geophys. Res.-Atmos., 123 11238-11261, https://doi.org/10.1029/2018JD028779, 2018.

Lin, H., Feng, X., Fu, T.-M., Tian, H., Ma, Y., Zhang, L., Jacob, D. J., Yantosca, R. M., Sulprizio, M. P., Lundgren, E. W., Zhuang, J., Zhang, Q., Lu, X., Zhang, L., Shen, L., Guo, J., Eastham, S. D., and Keller, C. A.: WRF-GC (v1.0): online coupling of WRF (v3.9.1.1) and GEOS-Chem (v12.2.1) for regional atmospheric chemistry modeling - Part 1: Description of the one-way model, Geosci. Model Dev., 13, 3241-3265, https://doi.org/10.5194/gmd-13-3241-2020, 2020.

Long, M. S., Yantosca, R., Nielsen, J. E., Keller, C. A., da Silva, A., Sulprizio, M. P., Pawson, S., and Jacob, D. J.: Development of a grid-independent GEOS-Chem chemical transport model (v9-02) as an atmospheric chemistry module for Earth system models, Geosci. Model Dev., 8, 595-602, https://doi.org/10.5194/gmd-8-595-2015, 2015.

Lorente, A., Folkert Boersma, K., Yu, H., Dörner, S., Hilboll, A., Richter, A., Liu, M., Lamsal, L. N., Barkley, M., De Smedt, I., Van Roozendael, M., Wang, Y., Wagner, T., Beirle, S., Lin, J.T., Krotkov, N., Stammes, P., Wang, P., Eskes, H. J., and Krol, M.: Structural uncertainty in air mass factor calculation for $\mathrm{NO}_{2}$ 
and HCHO satellite retrievals, Atmos. Meas. Tech., 10, 759-782, https://doi.org/10.5194/amt-10-759-2017, 2017.

Mari, C., Jacob, D. J., and Bechtold, P.: Transport and scavenging of soluble gases in a deep convective cloud, J. Geophys. Res.-Atmos., 105, 22255-22267, https://doi.org/10.1029/2000JD900211, 2000.

McDuffie, E., Smith, S., O’Rourke, P., Tibrewal, K., Venkataraman, C., Marais, E., Zheng, B., Crippa, M., Brauer, M., and Martin, R.: CEDS_GBD-MAPS: Global Anthropogenic Emission Inventory of $\mathrm{NOx}, \mathrm{SO}_{2}, \mathrm{CO}, \mathrm{NH}_{3}, \mathrm{NMVOCs}, \mathrm{BC}$, and OC from 1970-2017 (2020_v1.0), Zenodo [data set], https://doi.org/10.5281/zenodo.3754964, 2020.

McGregor, J. L. and Dix, M. R.: An updated description of the conformal-cubic atmospheric model, in: High resolution numerical modelling of the atmosphere and ocean, Springer, 51-75, 2008.

Miyakoda, K. and Rosati, A.: One-way nested grid models: The interface conditions and the numerical accuracy, Mon. Weather Rev., 105, 1092-1107, 1977.

Murray, L. T., Jacob, D. J., Logan, J. A., Hudman, R. C., and Koshak, W. J.: Optimized regional and interannual variability of lightning in a global chemical transport model constrained by LIS/OTD satellite data: IAV OF LIGHTNING CONSTRAINED BY LIS/OTD, J. Geophys. Res.-Atmos., 117, D20307, https://doi.org/10.1029/2012JD017934, 2012.

Palmer, P. I., Jacob, D. J., Chance, K., Martin, R. V., Spurr, R. J. D., Kurosu, T. P., Bey, I., Yantosca, R., Fiore, A., and Li, Q.: Air mass factor formulation for spectroscopic measurements from satellites: Application to formaldehyde retrievals from the Global Ozone Monitoring Experiment, J. Geophys. Res.-Atmos., 106, 14539-14550, https://doi.org/10.1029/2000JD900772, 2001.

Park, R., Pickering, K., Allen, D., Stenchikov, G., and FoxRabinovitz, M.: Global simulation of tropospheric ozone using the University of Maryland Chemical Transport Model (UMDCTM): 2. Regional transport and chemistry over the central United States using a stretched grid, J. Geophys. Res.-Atmos., 109, D09303, https://doi.org/10.1029/2003JD004269, 2004.

Punger, E. M. and West, J. J.: The effect of grid resolution on estimates of the burden of ozone and fine particulate matter on premature mortality in the USA, Air Qual. Atmos. Hlth., 6, 563573, https://doi.org/10.1007/s11869-013-0197-8, 2013.

Putman, W. M. and Lin, S.-J.: Finite-volume transport on various cubed-sphere grids, J. Comput. Phys., 227, 55-78, https://doi.org/10.1016/j.jcp.2007.07.022, 2007.

Ramshaw, J. D.: Conservative rezoning algorithm for generalized two-dimensional meshes, J. Comput. Phys., 59, 193-199, https://doi.org/10.1016/0021-9991(85)90141-X, 1985.

Rienecker, M. M., Suarez, M. J., Todling, R., Bacmeister, J., Takacs, L., Liu, H. C., Gu, W., Sienkiewicz, M., Koster, R. D., Gelaro, R., Stajner, I., and Nielsen, J. E.: The GEOS-5 Data Assimilation System: Documentation of Versions 5.0.1, 5.1.0, and 5.2.0., available at https://gmao.gsfc.nasa.gov/pubs/docs/Rienecker369. pdf (last access: 15 April 2021), 2008.

Schmidt, F.: Variable fine mesh in spectral global models, Beitr. Phys. Atmos., 50, 211-217, 1977.

Slingo, J., Bates, K., Nikiforakis, N., Piggott, M., Roberts, M., Shaffrey, L., Stevens, I., Vidale, P. L., and Weller, H.: Developing the next-generation climate system models: challenges and achievements, Philos. T. R. Soc. A-Math., 367, 815-831, 2009.
Srivastava, R. K., McRae, D., and Odman, M.: An adaptive grid algorithm for air-quality modeling, J. Comput. Phys., 165, 437472, 2000.

Stettler, M., Eastham, S., and Barrett, S.: Air quality and public health impacts of UK airports. Part I: Emissions, Atmos. Environ., 45, 5415-5424, https://doi.org/10.1016/j.atmosenv.2011.07.012, 2011.

Suarez, M., Trayanov, A., Hill, C., Schopf, P., and Vikhliaev, Y.: MAPL: a high-level programming paradigm to support more rapid and robust encoding of hierarchical trees of interacting high-performance components, in: Proceedings of the 2007 symposium on Component and framework technology in high-performance and scientific computing CompFrame '07, ACM Press, Montreal, Quebec, Canada, p. 11, https://doi.org/10.1145/1297385.1297388, 2007.

Tack, F., Merlaud, A., Iordache, M.-D., Pinardi, G., Dimitropoulou, E., Eskes, H., Bomans, B., Veefkind, P., and Van Roozendael, M.: Assessment of the TROPOMI tropospheric $\mathrm{NO}_{2}$ product based on airborne APEX observations, Atmos. Meas. Tech., 14, 615646, https://doi.org/10.5194/amt-14-615-2021, 2021.

The International GEOS-Chem User Community:geoschem/geoschem: GEOS-Chem 12.5.0 (12.5.0), Zenodo [code], https://doi.org/10.5281/zenodo.3403111, 2019.

The International GEOS-Chem User Community: geoschem/gchp: GCHP 13.0.0-alpha.3 (13.0.0-alpha.3), Zenodo [code], https://doi.org/10.5281/zenodo.4317978, 2020.

Thompson, M., Auer, B., Clune, T., Trayanov, A., Jiang, W., Norris, P., Lundgren, L., Sherman, E., Jamieson, W., Bindle, L., Eastham, S. D., Putman, B., and Vikhliaev, Y.: GEOSESM/MAPL: MAPL 2.2 Release (v2.2.0), Zenodo [code], https://doi.org/10.5281/zenodo.3903435, 2020.

Todling, R. and El Akkraoui, A.: The GMAO Hybrid EnsembleVariational Atmospheric Data Assimilation System: Version 2.0, available at https://gmao.gsfc.nasa.gov/pubs/docs/Todling1019. pdf (last access: 15 April 2021), 2018.

Tomita, H.: A stretched icosahedral grid by a new grid transformation, J. Meteorol. Soc. Jpn. Ser. II, 86, 107-119, 2008.

Tomlin, A., Berzins, M., Ware, J., Smith, J., and Pilling, M.: On the use of adaptive gridding methods for modelling chemical transport from multi-scale sources, Atmos. Environ., 31, 2945-2959, 1997.

Trieu, T. T. N., Goto, D., Yashiro, H., Murata, R., Sudo, K., Tomita, H., Satoh, M., and Nakajima, T.: Evaluation of summertime surface ozone in Kanto area of Japan using a semi-regional model and observation, Atmos. Environ., 153, 163-181, 2017.

Uchida, J., Mori, M., Nakamura, H., Satoh, M., Suzuki, K., and Nakajima, T.: Error and energy budget analysis of a nonhydrostatic stretched-grid global atmospheric model, Mon. Weather Rev., 144, 1423-1447, 2016.

Valin, L. C., Russell, A. R., Hudman, R. C., and Cohen, R. C.: Effects of model resolution on the interpretation of satellite NO2 observations, Atmos. Chem. Phys., 11, 11647-11655, https://doi.org/10.5194/acp-11-11647-2011, 2011.

van der Werf, G. R., Randerson, J. T., Giglio, L., van Leeuwen, T. T., Chen, Y., Rogers, B. M., Mu, M., van Marle, M. J. E., Morton, D. C., Collatz, G. J., Yokelson, R. J., and Kasibhatla, P. S.: Global fire emissions estimates during 1997-2016, Earth Syst. Sci. Data, 9, 697-720, https://doi.org/10.5194/essd-9-697-2017, 2017. 
Wang, Y. X., McElroy, M. B., Jacob, D. J., and Yantosca, R. M.: A nested grid formulation for chemical transport over Asia: Applications to $\mathrm{CO}$ : Nested grid co simulation over Asia, J. Geophys. Res.-Atmos., 109, D22307, https://doi.org/10.1029/2004JD005237, 2004.

Weng, H., Lin, J., Martin, R., Millet, D. B., Jaeglé, L., Ridley, D., Keller, C., Li, C., Du, M., and Meng, J.: Global high-resolution emissions of soil NOx, sea salt aerosols, and biogenic volatile organic compounds, Sci. Data, 7, 148, https://doi.org/10.1038/s41597-020-0488-5, 2020.

Wild, O. and Prather, M. J.: Global tropospheric ozone modeling: Quantifying errors due to grid resolution, J. Geophys. Res., 111, D11305, https://doi.org/10.1029/2005JD006605, 2006.

Yan, Y., Lin, J., Chen, J., and Hu, L.: Improved simulation of tropospheric ozone by a global-multi-regional two-way coupling model system, Atmos. Chem. Phys., 16, 2381-2400, https://doi.org/10.5194/acp-16-2381-2016, 2016.

Yan, Y.-Y., Lin, J.-T., Kuang, Y., Yang, D., and Zhang, L.: Tropospheric carbon monoxide over the Pacific during HIPPO: two-way coupled simulation of GEOS-Chem and its multiple nested models, Atmos. Chem. Phys., 14, 12649-12663, https://doi.org/10.5194/acp-14-12649-2014, 2014.
Zängl, G., Reinert, D., Rípodas, P., and Baldauf, M.: The ICON (ICOsahedral Non-hydrostatic) modelling framework of DWD and MPI-M: Description of the non-hydrostatic dynamical core, Q. J. Roy. Meteor. Soc., 141, 563-579, 2015.

Zhang, D.-L., Chang, H.-R., Seaman, N. L., Warner, T. T., and Fritsch, J. M.: A two-way interactive nesting procedure with variable terrain resolution, Mon. Weather Rev., 114, 1330-1339, 1986.

Zhao, X., Griffin, D., Fioletov, V., McLinden, C., Cede, A., Tiefengraber, M., Müller, M., Bognar, K., Strong, K., Boersma, F., Eskes, H., Davies, J., Ogyu, A., and Lee, S. C.: Assessment of the quality of TROPOMI high-spatial-resolution $\mathrm{NO}_{2}$ data products in the Greater Toronto Area, Atmos. Meas. Tech., 13, 2131 2159, https://doi.org/10.5194/amt-13-2131-2020, 2020.

Zhuang, J., Jacob, D. J., Lin, H., Lundgren, E. W., Yantosca, R. M., Gaya, J. F., Sulprizio, M. P., and Eastham, S. D.: Enabling High-Performance Cloud Computing for Earth Science Modeling on Over a Thousand Cores: Application to the GEOSChem Atmospheric Chemistry Model, J. Adv. Model. Earth Sy., 12, e2020MS002064, https://doi.org/10.1029/2020MS002064, 2020. 